Supporting Information

\title{
Dual Site-selective Presentation of Functional Handles on Protein- engineered Cowpea Chlorotic Mottle Virus-like Particles
}

\author{
Daan F. M. Vervoort, Robin Heiringhoff, Suzanne, B.P.E. Timmermans, Marleen H.M.E van
} Stevendaal, and Jan C. M. van Hest*

* $\quad$ Eindhoven University of Technology, Institute for Complex Molecular Systems PO Box 513 (STO 3.41), 5600 MB Eindhoven, The Netherlands. Email: j.c.m.v.hest@tue.nl 


\section{Contents}

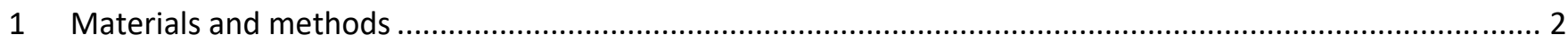

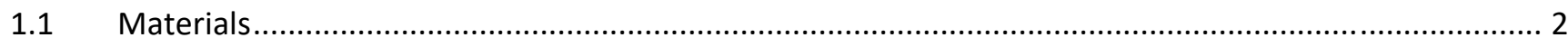

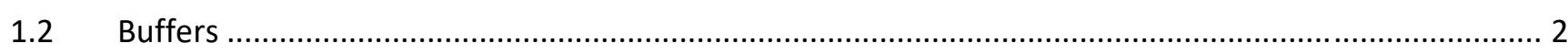

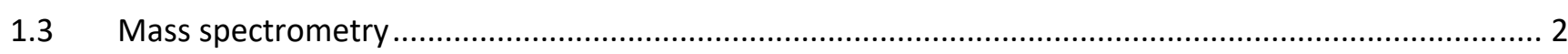

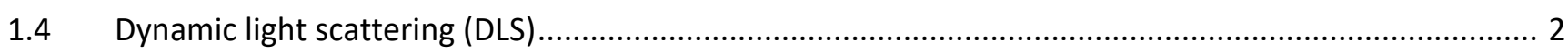

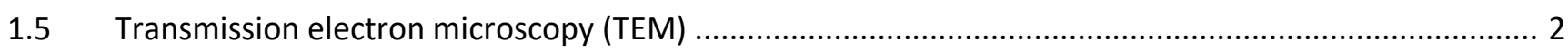

1.6 General protocol for the expression of $\mathrm{His}_{6}$-ELP-CCMV variants ...................................................... 3

1.7 Protocol for the expression of C59S-VW1-VW8 ELP-CCMV ........................................................... 3

1.8 Protocol for the expression of K65azF-VY1-VY8 ELP-CCMV ......................................................... 3

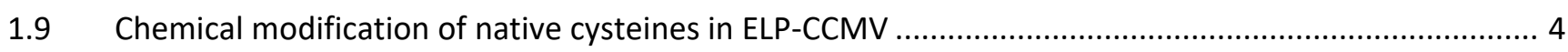

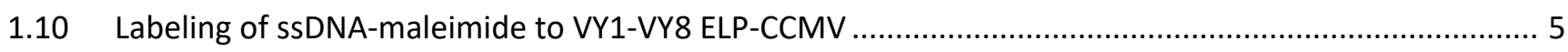

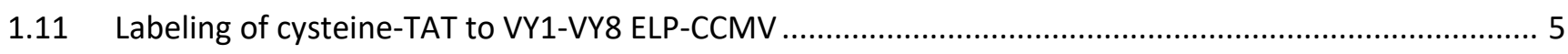

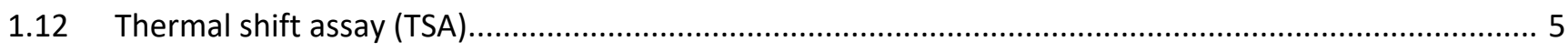

1.13 Stabilization of ELP-CCMV variants using the homobifunctional crosslinker DTSSP or BS3.................. 5

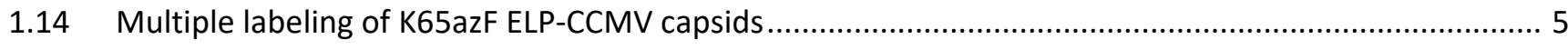

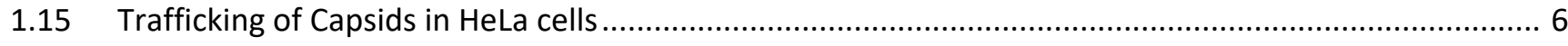

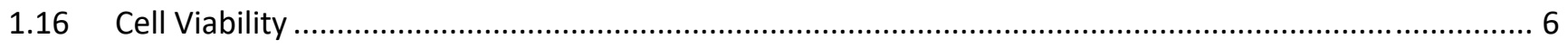

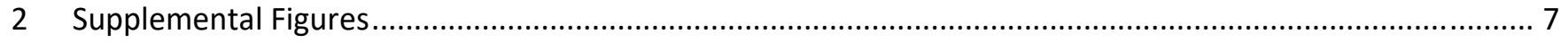

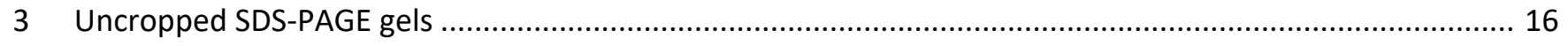

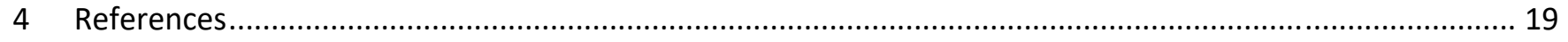




\section{Materials and methods}

\subsection{Materials}

Ampicillin and chloramphenicol were obtained from Sigma-Aldrich. Isopropyl $\beta$-D-1-thiogalactopyranoside (IPTG) was purchased from UBPBio. Ni-NTA agarose beads were obtained from Qiagen. DTSSP (3,3'dithiobis[sulfosuccinimidyl propionate, Dpnl, dNTPs and 2x Phusion High-Fidelity PCR mastermix were obtained from New England Biolabs. BS3 (bis(sulfosuccinimidyl)suberate) and SYPRO ${ }^{\text {TM }}$ Orange were purchased from Thermo Scientific. Sulfo-Cyanine5 maleimide, Sulfo-Cyanine5-DBCO and Sulfo-Cyanine3-DBCO were obtained from Lumiprobe.

\subsection{Buffers}

Table S1 - Composition of buffers

\begin{tabular}{ll}
\hline Name & Composition \\
\hline pH 5.0 capsid buffer & $50 \mathrm{mM} \mathrm{NaOAc}, 500 \mathrm{mM} \mathrm{NaCl}, 10 \mathrm{mM} \mathrm{MgCl}, 1$ mM EDTA, pH 5.0 \\
pH 7.5 $100 \mathrm{mM} \mathrm{NaCl}$ buffer & $50 \mathrm{mM} \mathrm{Tris} \cdot \mathrm{HCl}, 100 \mathrm{mM} \mathrm{NaCl}, 10 \mathrm{mM} \mathrm{MgCl}, 1 \mathrm{mM}$ EDTA, pH 7.5 \\
pH 7.5 $2000 \mathrm{mM} \mathrm{NaCl}$ buffer & $50 \mathrm{mM}$ Tris. HCl, $2500 \mathrm{mM} \mathrm{NaCl}, 10 \mathrm{mM} \mathrm{MgCl}$, 1 mM EDTA, pH 7.5 \\
PBS & $137 \mathrm{mM} \mathrm{NaCl}, 2.7 \mathrm{mM} \mathrm{KCl}$ and $10 \mathrm{mM}$ phosphate buffer solution \\
PBS $500 \mathrm{mM} \mathrm{NaCl}$ & $500 \mathrm{mM} \mathrm{NaCl}, 2.7 \mathrm{mM} \mathrm{KCl}$ and $10 \mathrm{mM}$ phosphate buffer solution \\
PBS $2000 \mathrm{mM} \mathrm{NaCl}$ & $2000 \mathrm{mM} \mathrm{NaCl}, 2.7 \mathrm{mM} \mathrm{KCl}$ and $10 \mathrm{mM}$ phosphate buffer solution
\end{tabular}

All buffers were filtered over a 0.2-micron filter prior to use.

\subsection{Mass spectrometry}

Protein mass characterization was performed using a High-Resolution LC-MS system consisting of a Waters ACQUITY UPLC I-Class system coupled to a Xevo G2 Quadrupole Time of Flight (Q-TOF). The system consisted of a Binary Solvent Manager and a Sample Manager with Fixed-Loop (SM-FL). Proteins were separated $(0.3 \mathrm{~mL} / \mathrm{min})$ on the column (Polaris C18A reverse phase column, $2.0 \times 100 \mathrm{~mm}$, Agilent) using an acetonitrile gradient in water $(15 \%$ to $75 \%, v / v)$ supplemented with formic acid $(0.1 \%, v / v)$ before analysis in positive mode in the mass spectrometer. Deconvoluted mass spectra were obtained using the MaxENT1 algorithm in the Masslynx v4.1 (SCN862) software. Isotopically averaged molecular weights were calculated using the 'Protein Calculator v3.4' at http://protcalc.sourceforge.net. Protein samples were desalted by spin-filtration (Amicon ${ }^{\circledR}$ Ultra $0.5 \mathrm{~mL}$ ) in MilliQ prior to measurement.

\subsection{Dynamic light scattering (DLS)}

DLS measurements were performed on a Malvern Zetasizer Nano ZSP at indicated temperature. Samples (20 $\mu \mathrm{M}$, unless stated otherwise) were centrifuged twice prior to analysis. Buffers were filtered prior to use. All measurements were performed in triplicate and the average measurements were plotted.

\subsection{Transmission electron microscopy (TEM)}

TEM grids (FCF-200-Cu, EMS) were glow-discharged using a Cressington 206 carbon coater and power unit. Protein samples $(0.2 \mathrm{mg} / \mathrm{mL}, 5 \mu \mathrm{L})$ were applied on the glow-discharged grids and incubated for 1-5 min. Then, the grid was negatively stained by applying $2 \%$ uranyl acetate in water $(5 \mu \mathrm{L})$. The staining solution was removed after 15 seconds and the grid was allowed to dry for at least 15 minutes. The samples were then studied on a FEI Tecnai 20 TEM (type Sphera) (operated at 200 kV, equipped with a LaB 6 filament and a FEI B-Ceta CCD camera). 


\subsection{General protocol for the expression of His ${ }_{6}-E L P-C C M V$ variants}

The $p E T-15 b-H_{6}-V Y 1-V Y 8-E L P-C C M V(\Delta N 26)$ and pET-15b- $H_{6}-V W 1-V W 8-E L P-C C M V(\Delta N 26)$ vectors encoding for the ELP-CCMV variants used in this paper were previously constructed. ${ }^{1,2}$ ELP-CCMV capsid protein variants were expressed according to a standard expression procedure. Briefly, E.coli BLR(DE3)pLysS glycerol stocks containing the $\mathrm{pET}-15 \mathrm{~b}-\mathrm{H}_{6}-\mathrm{VY} 1-\mathrm{VY} 8-\mathrm{ELP}-\mathrm{CCMV}(\Delta \mathrm{N} 26)$ and $\mathrm{pET}-15 \mathrm{~b}-\mathrm{H}_{6}-\mathrm{VW} 1-\mathrm{VW} 8-\mathrm{ELP}-\mathrm{CCMV}(\Delta \mathrm{N} 26)$ vectors were used for an overnight culture at $37{ }^{\circ} \mathrm{C}$ in lysogeny broth medium (LB , $\left.50 \mathrm{~mL}\right)$, containing ampicillin $(100 \mathrm{mg} / \mathrm{L})$ and chloramphenicol (50 mg/L). 2xTY medium ( $1 \mathrm{~L})$, containing ampicillin $(100 \mathrm{mg} / \mathrm{L})$ was inoculated with the overnight culture and grown at $37{ }^{\circ} \mathrm{C}$ till an optimal optical density was reached (OD600 between 0.4 and 0.6). Protein expression was subsequently induced by addition of IPTG $(1 \mathrm{mM})$ and the culture was incubated at $30^{\circ} \mathrm{C}$ for 6 hours. Cells were harvested by centrifugation $\left(2700 \mathrm{~g}, 15 \mathrm{~min}\right.$, and $\left.4{ }^{\circ} \mathrm{C}\right)$ and pellets were stored overnight at -20 ${ }^{\circ} \mathrm{C}$. The cell pellet was resuspended in lysis buffer $\left(50 \mathrm{mM} \mathrm{NaH}_{2} \mathrm{PO}_{4}, 300 \mathrm{mM} \mathrm{NaCl}, 10 \mathrm{mM}\right.$ imidazole, pH $8.0 ; 25$ $\mathrm{mL}$ ). Cell lysis was performed by ultrasonic disruption (7-10 times 30 seconds, 70\% amplitude, Branson Sonifier 150). Cell lysate was then centrifuged $\left(16.400 \mathrm{~g}, 15 \mathrm{~min}, 4^{\circ} \mathrm{C}\right)$ to remove bacterial debris. The supernatant was incubated with Ni-NTA agarose beads ( $3 \mathrm{~mL}$ ) for 1 hour at $4{ }^{\circ} \mathrm{C}$, followed by column loading. The flow-through was collected and the column was washed twice with wash buffer $\left(50 \mathrm{mM} \mathrm{NaH}_{2} \mathrm{PO}_{4}, 300 \mathrm{mM} \mathrm{NaCl}, 20 \mathrm{mM}\right.$ imidazole, $\mathrm{pH}$ 8.0; $20 \mathrm{~mL}$ ). The proteins of interest were eluted from the column with elution buffer $\left(50 \mathrm{mM} \mathrm{NaH}_{2} \mathrm{PO}_{4}, 300\right.$ $\mathrm{mM} \mathrm{NaCl}, 250 \mathrm{mM}$ imidazole, $\mathrm{pH} 8.0 ; 1$ time $0.5 \mathrm{~mL}, 7$ times $1.5 \mathrm{~mL}$ ) and fractions containing histidine-tagged ELPCCMV were combined and dialyzed against $\mathrm{pH} 7.5$ dimer buffer $(50 \mathrm{mM}$ Trizma base, $500 \mathrm{mM} \mathrm{NaCl}, 10 \mathrm{mM} \mathrm{MgCl}$, $1 \mathrm{mM}$ EDTA, pH 7.5; 3 times 30 minutes using a 12-14 kDa tubing). Proteins were dialyzed against pH 5.0 capsid buffer ( $50 \mathrm{mM}$ Trizma base, $500 \mathrm{mM} \mathrm{NaCl}, 10 \mathrm{mM} \mathrm{MgCl}$, $1 \mathrm{mM}$ EDTA, pH 5.0; 2 times 30 minutes, followed by overnight dialysis using a 12-14 kDa tubing) for stable storage at $4^{\circ} \mathrm{C}$. Proteins were characterized by SDS-PAGE, Q-TOF, DLS and SEC (Fig. S1 and Fig. S2). Protein expression yields as well as Q-TOF results are listed in Table S2.

\subsection{Protocol for the expression of C59S-VW1-VW8 ELP-CCMV}

Site-directed mutagenesis was performed using designed primers (Table S4) via the strategy developed by Liu et al. $^{3} 0.2 \mathrm{ng} / \mu \mathrm{L}$ pET-15b-H ${ }_{6}$ VW1-VW8-ELP-CCMV $(\Delta \mathrm{N} 26)$ was incubated with $200 \mu \mathrm{M}$ dNTPs, $25 \mu \mathrm{L} 2 x$ Phusion HighFidelity PCR master mix and $1 \mu \mathrm{M}$ of both the forward and reverse primer in a final volume of $50 \mu \mathrm{L}$. Site-directed mutagenesis was performed using the following cycle; $98^{\circ} \mathrm{C}$ for $5 \mathrm{~min}$, followed by a repeating cycle of $98^{\circ} \mathrm{C}$ for $1 \mathrm{~min}, 67^{\circ} \mathrm{C}$ for $1 \mathrm{~min}, 72^{\circ} \mathrm{C}$ for $15 \mathrm{~min}$, and ended with $67^{\circ} \mathrm{C}$ for $1 \mathrm{~min}$ followed by $72{ }^{\circ} \mathrm{C}$ for 30 minutes. Dpnl digestion was then performed to remove the pET-15b- ${ }_{6}-\mathrm{VW} 1-\mathrm{VW} 8-\mathrm{ELP}-\mathrm{CCMV}(\Delta \mathrm{N} 26)$ (with $1 \mu \mathrm{L}$ Dpnl). The reaction mixture was incubated for 1 hour at $37^{\circ} \mathrm{C} .20 \mu \mathrm{L}$ of the PCR mixtures was then transformed into XL-1 Blue competent cells in order to perform plasmid amplification. Plasmids were then isolated and transformed into E.coli BLR(DE3)pLysS and analyzed by Sanger sequencing. Expression and purification were performed as described above. The protein was characterized by SDS-PAGE, Q-TOF, DLS and SEC (Fig. S6). Protein expression yields as well as Q-TOF results are listed in Table S2. The position C59 is based on the position of the amino acid in native CCMV capsids.

\subsection{Protocol for the expression of K65azF-VY1-VY8 ELP-CCMV}

Site-directed mutagenesis was performed first to substitute the amber for an ochre stop-codon, using designed primers (Table S5) via the strategy developed by Liu et al. ${ }^{3}$ Site-directed mutagenesis was repeated with the newly obtained plasmid for introduction of the amber codon at position K65. Plasmids were then isolated and transformed into E.coli BLR(DE3)pLysS and analyzed by Sanger sequencing. Expression and purification were performed as described above. The protein was characterized by SDS-PAGE, Q-TOF, DLS and SEC (Fig. 3 and Fig. 4). Protein expression yields as well as Q-TOF results are listed in Table S2. The position K65 is based on the position of the amino acid in native CCMV capsids. 
Table S2 - Expression yields and Q-TOF results of the ELP-CCMV variants

\begin{tabular}{lccc}
\hline Name & Yield (mg/L) & \multicolumn{2}{c}{ Q-TOF results } \\
\hline & & Calculated MW (Da) & Observed MW (Da) \\
VY1-VY8 ELP-CCMV & 49 & 22381.5 & 22381 \\
VW1-VW8 ELP-CCMV & 28 & 22427.6 & 22427 \\
C59S VW1-VW8 ELP-CCMV & 10 & 22411.5 & 22411 \\
K65azF VY1-VY8 ELP-CCMV & 22 & 22441.6 & 22442
\end{tabular}

Table S3 - Amino Acid sequences of the ELP-CCMV variants

\begin{tabular}{|c|c|}
\hline Name & Sequence \\
\hline VY1-VY8 ELP-CCMV & $\begin{array}{l}\text { GHHHHHHVPGYGVPGLGVPGVGVPGLGVPGVGVPGLGVPGGGVPGYGVPGLGLEVVQPVIVEPIASGQGKAIKAWTGYSVSK } \\
\text { WTASCAAAEAKVTSAITISLPNELSSERNKQLKVGRVLLWLGLLPSVSGTVKSCVTETQTTAAASFOVALAVADNSKDVVAAMYP } \\
\text { EAFKGITLEQLTADLTIYLYSSAALTEGDVIVHLEVEHVRPTFDDSFTPVY }\end{array}$ \\
\hline VW1-VW8 ELP-CCMV & $\begin{array}{l}\text { GHHHHHHVPGWGVPGLGVPGVGVPGLGVPGVGVPGLGVPGGGVPGWGVPGLGLEVVQPVIVEPIASGQGKAIKAWTGYSV } \\
\text { SKWTASCAAAEAKVTSAITISLPNELSSERNKQLKVGRVLLWLGLLPSVSGTVKSCVTETQTTAAASFQVALAVADNSKDVVAAM } \\
\text { YPEAFKGITLEQLTADLTIYLYSSAALTEGDVIVHLEVEHVRPTFDDSFTPVY }\end{array}$ \\
\hline C59S VW1-VW8 ELP-CCMV & $\begin{array}{l}\text { GHHHHHHVPGWGVPGLGVPGVGVPGLGVPGVGVPGLGVPGGGVPGWGVPGLGLEVVQPVIVEPIASGQGKAIKAWTGYSV } \\
\text { SKWTASSAAAEAKVTSAITISLPNELSSERNKQLKVGRVLLWLGLLPSVSGTVKSCVTETQTTAAASFQVALAVADNSKDVVAAM } \\
\text { YPEAFKGITLEQLTADLTIYLYSSAALTEGDVIVHLEVEHVRPTFDDSFTPVY }\end{array}$ \\
\hline K65azF VY1-VY8 ELP-CCMV & $\begin{array}{l}\text { GHHHHHHVPGYGVPGLGVPGVGVPGLGVPGVGVPGLGVPGGGVPGYGVPGLGLEVVQPVIVEPIASGQGKAIKAWTGYSVSK } \\
\text { WTASCAAAEA(azF)VTSAITISLPNELSSERNKQLKVGRVLLWLGLLPSVSGTVKSCVTETQTTAAASFQVALAVADNSKDVVAA } \\
\text { MYPEAFKGITLEQLTADLTIYLYSSAALTEGDVIVHLEVEHVRPTFDDSFTPVY }\end{array}$ \\
\hline
\end{tabular}

Table S4 - DNA sequence (primers) for the site-directed mutagenesis of C59S

\begin{tabular}{|c|c|}
\hline Name & Sequence $\left(5^{\prime} \rightarrow 3^{\prime}\right)$ \\
\hline C59S F & CGCCTCT AGT GCGGCTG CCGAAGCTAAAGTAACCTCGGCTATAACTATCTCTCTCCCTA \\
\hline C59S R & CAGCCGC ACT AGAGGCG GTCCACTTCGATACGCTGTAACCGGTCCATG \\
\hline
\end{tabular}

Table S5 - DNA sequence (primers) for the site-directed mutagenesis of Ochre and Amber stop-codons

\begin{tabular}{|c|c|}
\hline Name & Sequence $\left(5^{\prime} \rightarrow 3^{\prime}\right)$ \\
\hline 'Amber to Ochre' $\mathbf{F}$ & CCGGTGTAT TAA GGATCCGGC TGCTAACAAAGCCCGAAAGGAAGCTGAGTTGG \\
\hline 'Amber to Ochre' $\mathbf{R}$ & 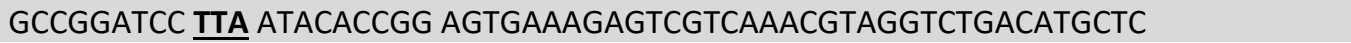 \\
\hline K65Amber $\mathbf{F}$ & GCCGAAGCT IAG GTAACCTCG GCTATAACTATCTCTCTCCCTAATGAGCTATCGTCCGAAAGGAACAA \\
\hline K65Amber R & CGAGGTTAC CTA AGCTTCGGC AGCCGCACAAGAGGCGGTCCAC \\
\hline
\end{tabular}

\subsection{Chemical modification of native cysteines in ELP-CCMV}

VY1-VY8 ELP-CCMV capsids were first dialyzed to pH $7.5100 \mathrm{mM} \mathrm{NaCl}$, followed by pH $7.5500 \mathrm{mM} \mathrm{NaCl}$. Capsids were then analysed by DLS to verify their assembly state. Native CCMV capsids were obtained by incubation of capsid proteins and heparin in a 6.5:1 molar ratio. Both capsids were then analysed by DLS to verify their assembly state (Fig. S3). As a negative control, sulfo-Cyanine5-maleimide (1.25 mM) was incubated for 2 hours at room temperature, $850 \mathrm{rpm}$ with $12.5 \mathrm{mM} \beta$-mercaptoethanol to obtain an unreactive Cy5 dye to exclude unspecific binding to CCMV. ELP-CCMV and heparin stabilized CCMV capsids (final concentration of $20 \mu \mathrm{M}$ ) were then incubated with either sulfo-Cyanine5-maleimide or unreactive sulfo-Cyanine5 for 2 hours at 850 rpm (CP:Dye, 1:5). Successful labelling was analysed by reducing SDS-PAGE and illumination (Cy5 excitation at $630 \mathrm{~nm}$ ) with a LED light source (LED Trans illuminator BT509) and emission through a 670/10 nm (Cy5) emission filter (right), followed by Coomassie staining. 


\subsection{Labeling of SSDNA-maleimide to VY1-VY8 ELP-CCMV}

VY1-VY8 ELP-CCMV capsids (100 $\mu \mathrm{M})$ were first dialyzed to pH $7.5100 \mathrm{mM} \mathrm{NaCl}$, followed by pH $7.5500 \mathrm{mM} \mathrm{NaCl}$. Capsids were then analysed by DLS to verify their assembly state. As a negative control, ssDNA-maleimide was incubated for 2 hours at room temperature, $850 \mathrm{rpm}$ with $20 \mathrm{mM}$ TCEP to obtain an unreactive ssDNA to exclude unspecific binding to CCMV capsids (final concentration of $20 \mu \mathrm{M}$ ). The capsids were then incubated with either ssDNA-maleimide or unreactive ssDNA for 2 hours at $850 \mathrm{rpm}$ (CP:ssDNA, 1:5). Successful labelling was analysed by reducing SDS-PAGE stained with SYBR Gold, followed by Coomassie staining (Figure S4).

\subsection{Labeling of cysteine-TAT to VY1-VY8 ELP-CCMV}

VY1-VY8 ELP-CCMV capsids were first buffer exchanged to PBS $2000 \mathrm{mM} \mathrm{NaCl}$, followed by buffer exchange towards PBS $500 \mathrm{mM} \mathrm{NaCl}$. Capsids $(20 \mu \mathrm{M})$ were incubated with the cysteine-TAT peptide $(100 \mu \mathrm{M})$ overnight at room temperature, $750 \mathrm{rpm}$. SDS-PAGE samples (final protein concentration $2.5 \mu \mathrm{M}$ ) were made by either mixing with 4x Laemmli Sample Buffer (Bio-rad) or with 4x leammli sample buffer containing $50 \mu \mathrm{M}$ DTT. The reaction mixture was analysed by SDS-PAGE and stained with Coomassie (Figure S5). Next, the reaction mixture was dialyzed (12-14 kDa MWCO) towards PBS 500mM NaCl to purify the capsids and analyzed by both DLS and Q-TOF.

\subsection{Thermal shift assay (TSA)}

Capsids were diluted to a concentration of $20 \mu \mathrm{M}$ in $\mathrm{pH} 7.5$ Buffer. In the same Buffer, SYPRO ${ }^{\text {TM }}$ Orange (ThermoFisher) (5000x stock concentration) was diluted to a $4 x$ concentrated SYPRO ${ }^{\text {TM }}$ Orange solution. Next, 10 $\mu \mathrm{l}$ of protein was placed into a 96 -well plate (96 Fast PCR-PI, Sarstedt) and $30 \mu \mathrm{l}$ of the diluted SYPRO ${ }^{\text {TM }}$ Orange mix was added (final protein concentration $5 \mu \mathrm{M}$ ). The plate was spun down, and measurements were carried out in a thermocycler (CFX96 Real Time System, Biorad). A temperature gradient was performed from $25^{\circ} \mathrm{C}$ to $90^{\circ} \mathrm{C}$ in steps of $1^{\circ} \mathrm{C}$. Each step the temperature was equilibrated for 15 seconds. SYPRO ${ }^{\mathrm{TM}}$ Orange was excited at $490 \mathrm{~nm}$ and the emission at $580 \mathrm{~nm}$ was measured using a microliter reader. Global minimum of the first derivation of the fluorescent signal provides the melting temperature for the capsids (Figure S10).

\subsection{Stabilization of ELP-CCMV variants using the homobifunctional crosslinker DTSSP or} BS3.

K65azF VY1-VY8 ELP-CCMV capsids were first buffer exchanged to PBS $2000 \mathrm{mM} \mathrm{NaCl}$, followed by buffer exchange towards PBS $500 \mathrm{mM} \mathrm{NaCl}$. Prior stabilization, the capsid assembly state was verified with DLS. Capsids $(100 \mu \mathrm{M})$ were then incubated with either DTSSP or BS3 $(1 \mathrm{mM})$ for 1 hour, $650 \mathrm{rpm}, 21^{\circ} \mathrm{C}$. Excess of homobifunctional crosslinker was removed by extensive dialysis towards PBS using 12-14 kDa MWCO dialysis tubing. Stabilization of capsids was analyzed by SDS-PAGE (Figure S12).

\subsection{Multiple labeling of K65azF ELP-CCMV capsids}

K65azF VY1-VY8 ELP-CCMV capsids $(100 \mu \mathrm{M})$ were first stabilized by the homobifunctional crosslinker BS3. Next, stabilized capsids $(50 \mu \mathrm{M})$ were conjugated to the cysteine-TAT peptide (ratio CP:TAT, 1:0.5) by incubation overnight at $21^{\circ} \mathrm{C}$. Both stabilized capsids and TAT conjugated stabilized capsids $(25 \mu \mathrm{M})$ were then incubated with DBCO-Cyanine5 (ratio CP:Cy5, 1:1) for 1 hour at $21^{\circ} \mathrm{C}$. Capsids were analyzed by SDS-PAGE (Figure S13A) and TEM (Figure S13B). 


\subsection{Trafficking of Capsids in HeLa cells}

The day prior to the experiment, 12000 cells/well were seeded to a 96-well plate (Nunc ${ }^{\mathrm{TM}}$ MicroWell $^{\mathrm{TM}}$ 96-Well Microplates, ThermoFisher) and grown overnight at $37^{\circ} \mathrm{C}, 5 \% \mathrm{CO}_{2}$ in $\mathrm{Gibco}^{\mathrm{TM}} \mathrm{RPMI} 1640$ Medium (ATCC Modification). The next day, the medium was removed from the well by careful aspiration and Opti-MEM (ThermoFisher) was added to the cells. Stabilized capsids (K65azF ELP-CCMV), Cy5 conjugated capsids (Cy5 K65azF ELP-CCMV) and dual conjugated capsids with both cysteine-TAT and Cy5 (TAT K65azF ELP-CCMV) were diluted to $1 \mu \mathrm{M}$ in Opti-MEM. After $30 \mathrm{~min}$ incubation at $37^{\circ} \mathrm{C}$ and $5 \% \mathrm{CO}_{2}$ the OptiMEM was carefully aspirated and the $1 \mu \mathrm{M}$ of capsids in Opti-MEM were added to the cells for 3 hours. The cells were then washed three times and imaged and measured in OptiMEM by the epi-fluorescence microscope (Zeiss Axio Observer D1). Experiments were performed in triplicates. In order to obtain biological triplicates, the experiment was repeated varying the batch of HeLa cells, passage number and the multiple labeling protocol was performed again to demonstrate reproducibility of the capsids containing both TAT and Cyanine5. For confocal laser scanning microscopy (Leica TCS SP5X), cells were incubated with Hoechst staining for 20 minutes, followed by lysotracker green DND-26 for 40 minutes prior to the measurements (Figure S14).

\subsection{Cell Viability}

In order to determine whether the capsids accumulated in living cells, HeLa cells were cultured as described above. $1 \mu \mathrm{M}$ capsids were now incubated for 24 hours. As a negative control, cells were incubated for 2 minutes with cell lysis buffer (cell-signaling) diluted in Opti-MEM. Alamar Blue reagent was diluted in Opti-MEM according to the manual and incubated for 1 hour. Cell viability was measured using a SPARK ${ }^{\circledR} 10 \mathrm{M}$ multimode microplate reader (Tecan) and data was plotted by normalization to the positive control (HeLa cells in medium) (Figure S15). 


\section{Supplemental Figures}

A. SDS-PAGE B.

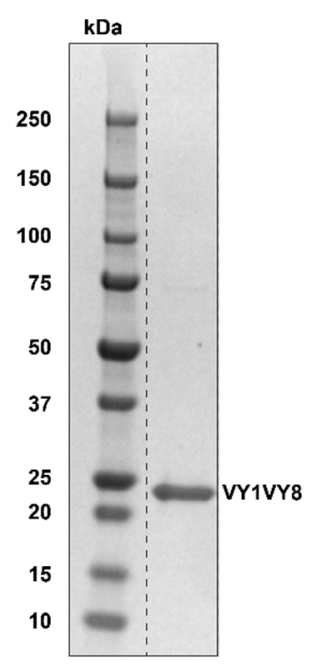

C.

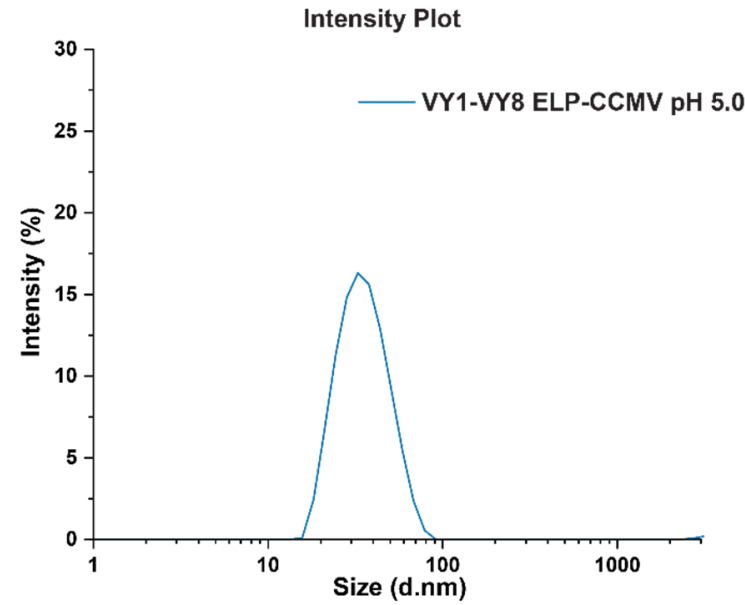

.
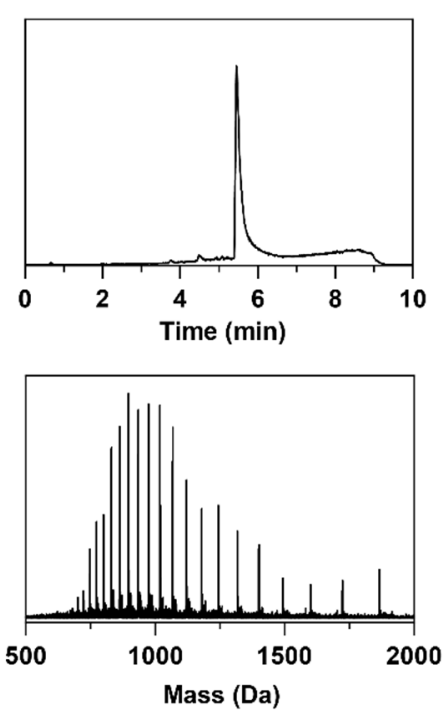

LC-MS Q-TOF

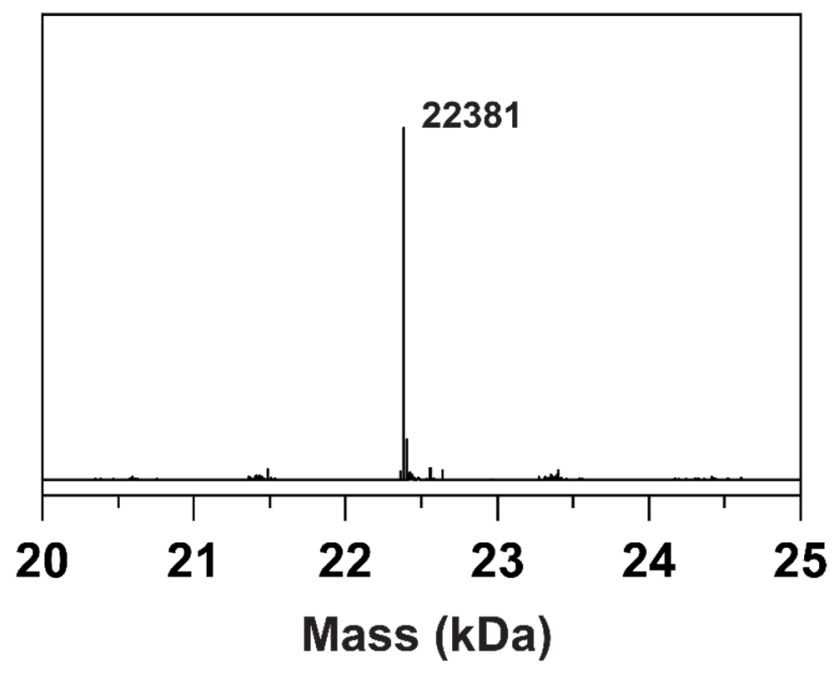

\section{5}

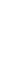


A. SDS-PAGE

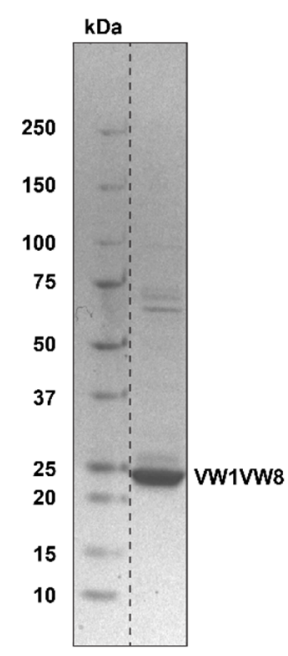

C.
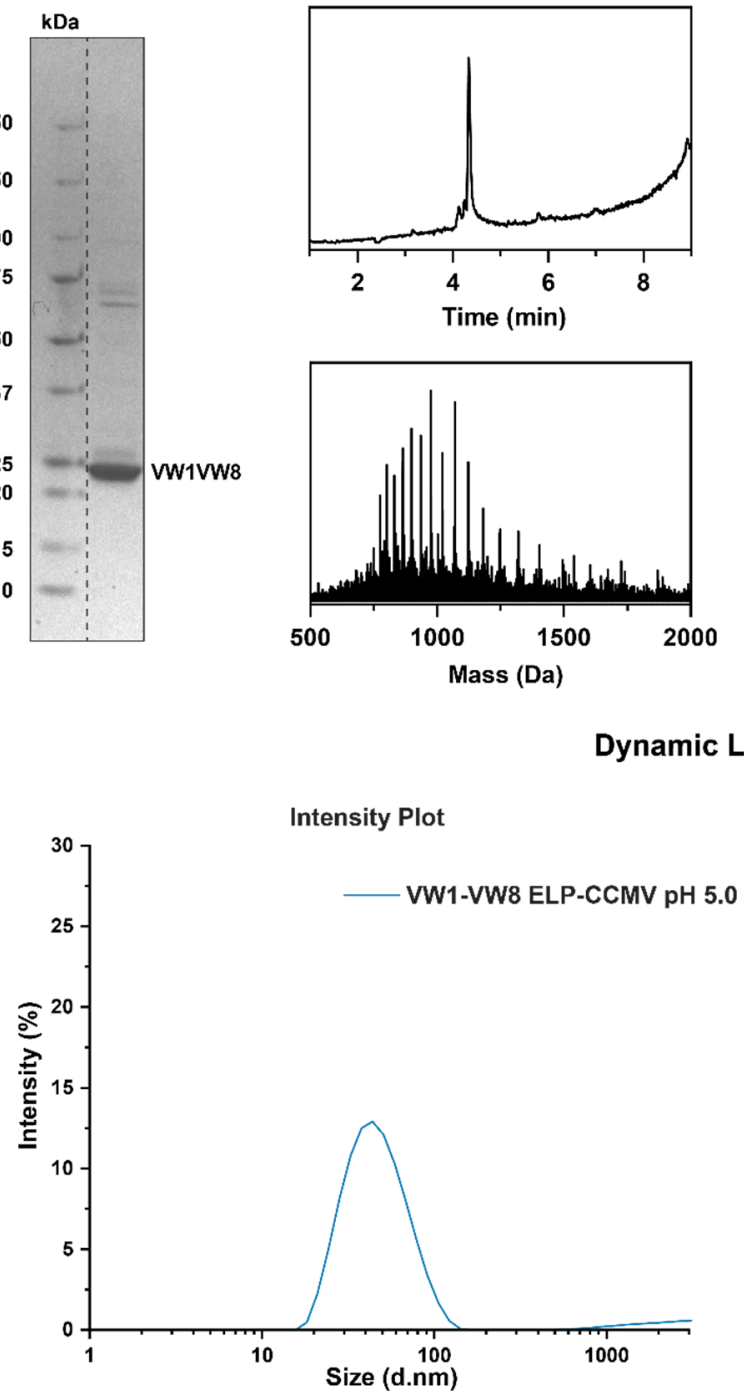

LC-MS Q-TOF

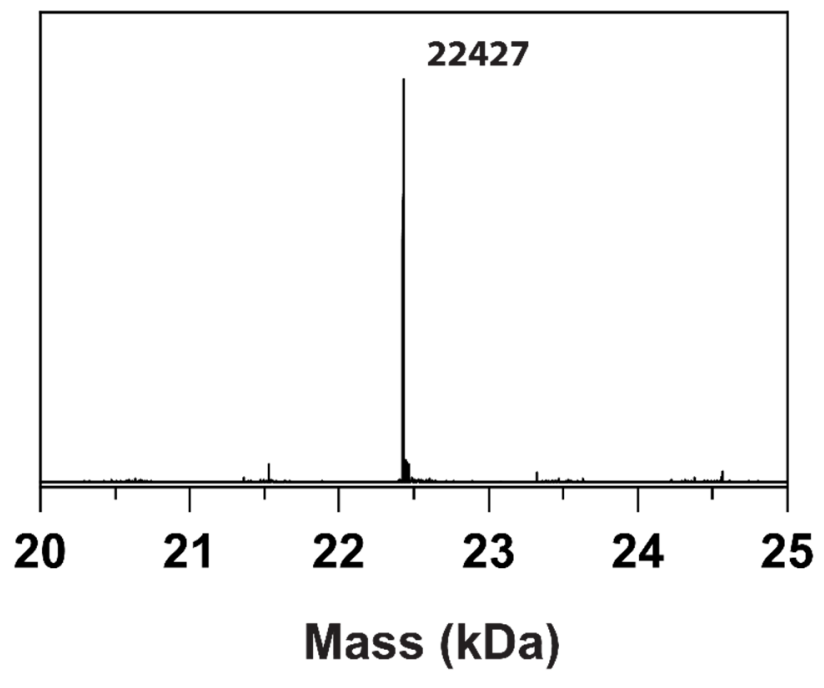

Dynamic Light Scattering

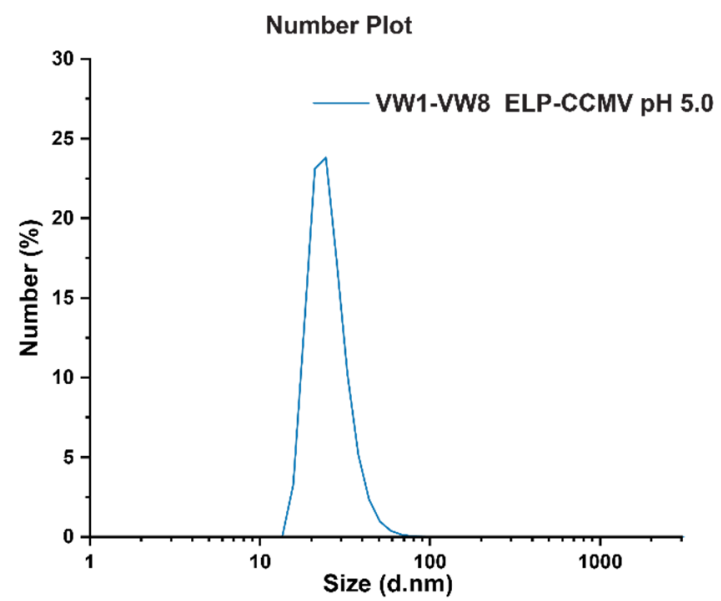

Figure S2: Characterization of purified VW1-VW8 ELP-CCMV: A. SDS-PAGE; B. LC-MS Q-TOF, total ion count chromatogram (top left), $\mathrm{m} / \mathrm{z}$ spectrum (bottom left) and mass spectrum (right), Calculated MW 22427.6 Da, Observed 22427 Da; C. Dynamic Light Scattering, Intensity plot (Left), Number plot (Right). 


\section{Dynamic Light Scattering}
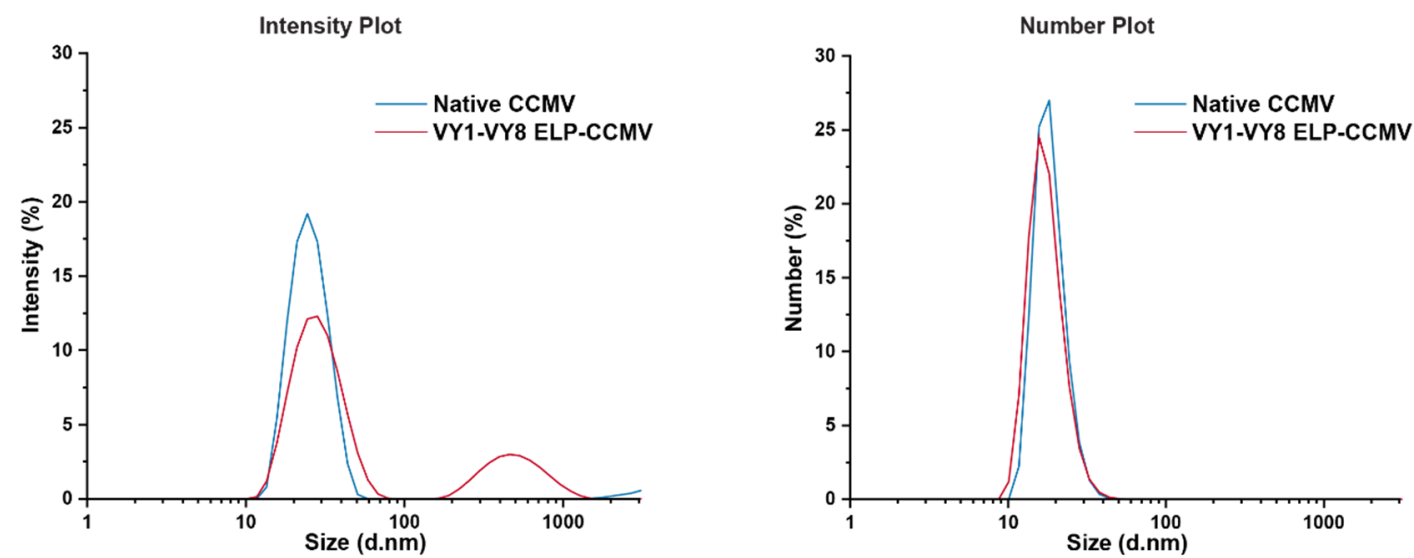

Figure S3: Assembly state of native CCMV (heparin stabilized) and VY1-VY8 ELP-CCMV capsids $(T=1)$ at physiological pH prior to maleimide labeling. Dynamic Light Scattering, Intensity plot (Left), Number plot (Right).

A.

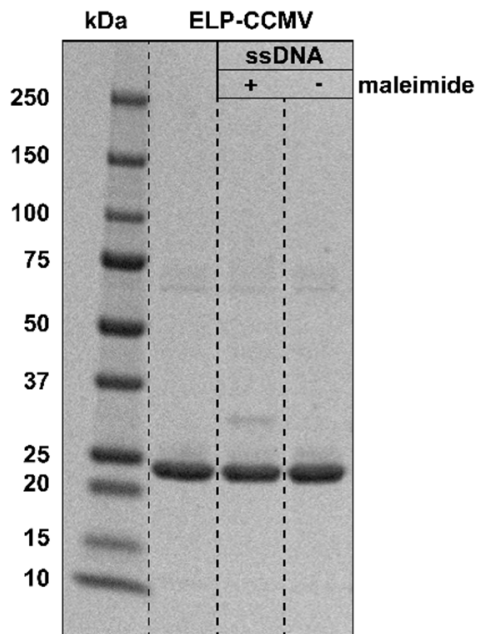

SDS-PAGE

ELP-CCMV

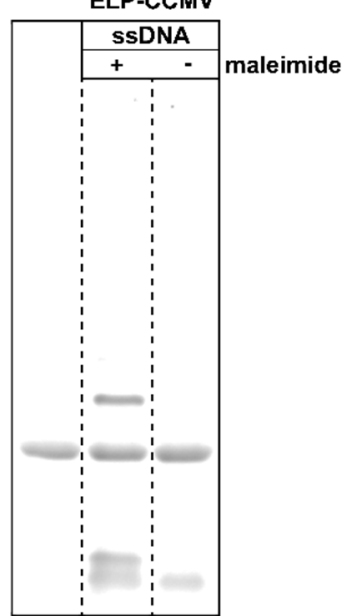

B. Transmission Electron Microscopy

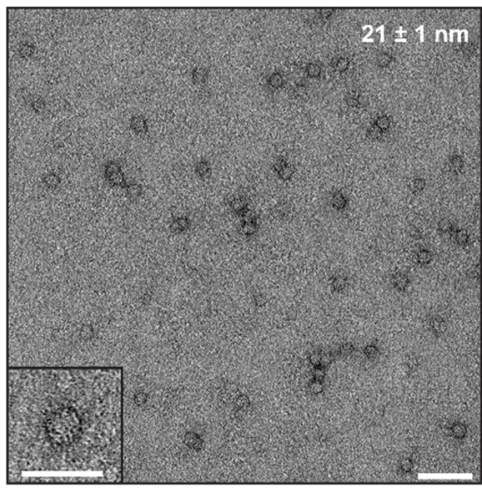

ssDNA labeled VY1-VY8 ELP-CCMV (ELP-induced)

Figure S4: Characterization of SsDNA labeled VY1-VY8 ELP-CCMV. A. SDS-PAGE analysis. Protein (Coomassie) staining (left), Nucleic acid staining (SYBR Gold) (right). SDS-PAGE analysis demonstrated successful conjugation of ssDNA to the capsid proteins with a yield of $9 \%$ ( 5 ssDNA per $T=1$ capsid). B. Transmission electron microscopy of ELP-induced ssDNA labeled capsids (21 $\pm 1 \mathrm{~nm} ; \mathrm{N}=34)$, Scale bar $100 \mathrm{~nm}$, zoomed-scale bar $50 \mathrm{~nm}$. 
A. SDS-PAGE

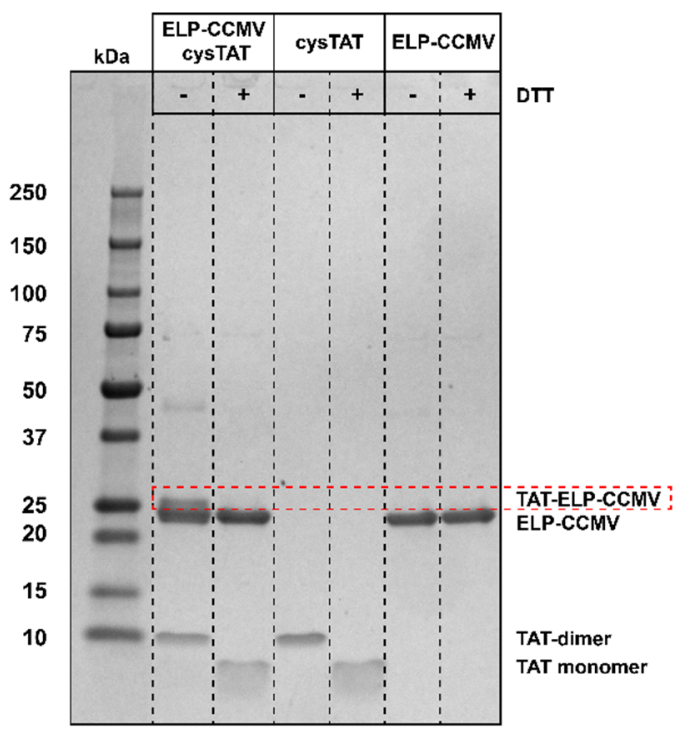

B. LC-MS Q-TOF

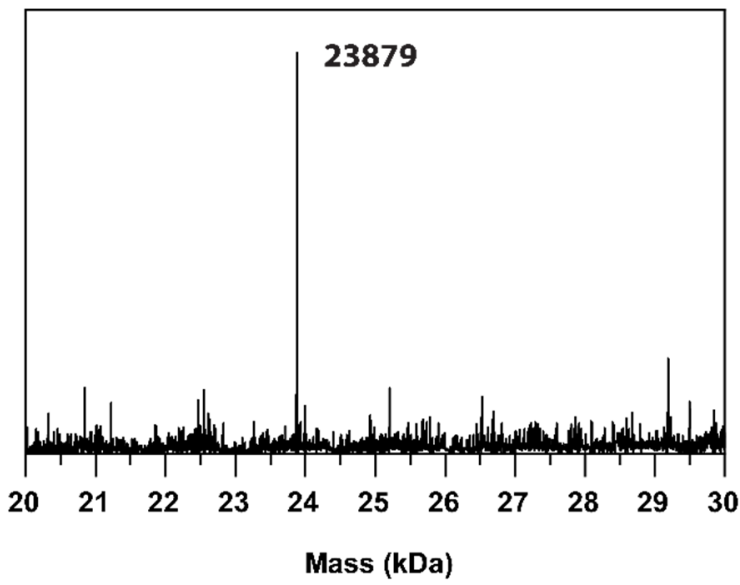

c.

Dynamic Light Scattering
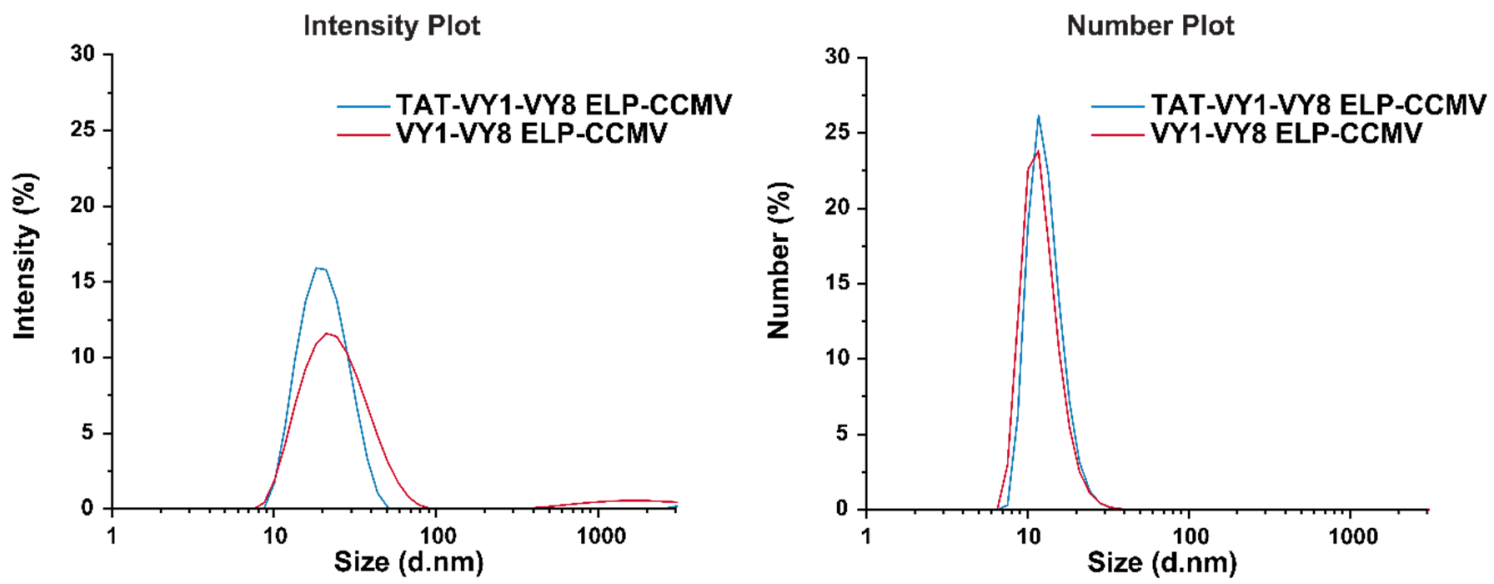

Figure S5: Characterization of TAT labeled VY1-VY8 ELP-CCMV. A. SDS-PAGE analysis of the labeling reaction using a protein (Coomassie) stained gel. SDS-PAGE analysis demonstrated successful conjugation of TAT to the capsid proteins with a yield of approximately $30 \%$ ( 18 TAT peptides per $T=1$ capsid). B. LC-MS Q-TOF, mass spectrum of purified TAT labeled capsid proteins; Calculated MW 23879.3 Da, Observed 23879 Da. C. Dynamic Light Scattering, Intensity plot (Left), Number plot (Right) of unlabeled and TAT labeled ELP-induced capsids. 


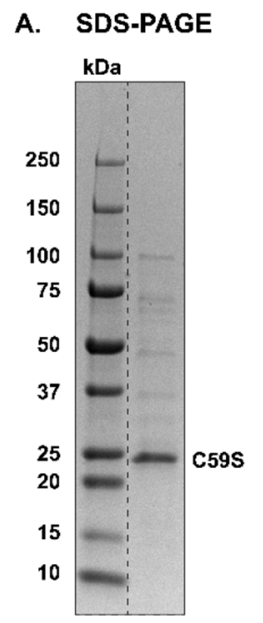

B.

LC-MS Q-TOF

c.

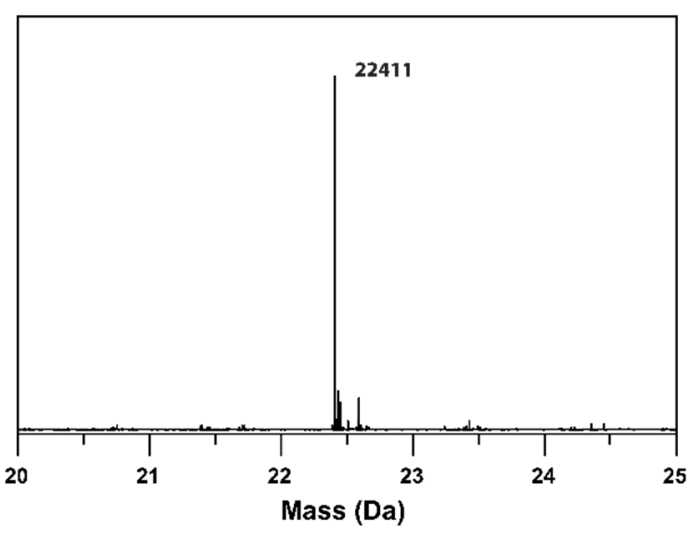

Transmission Electron Microscopy

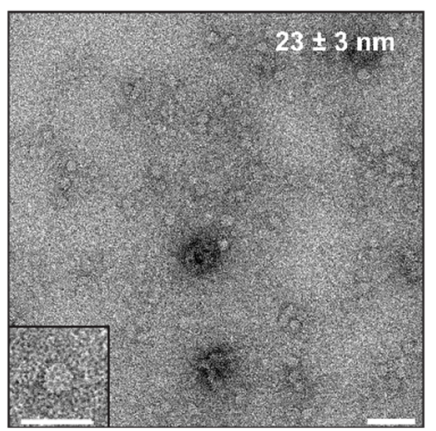

ELP-induced $T=1$ capsids

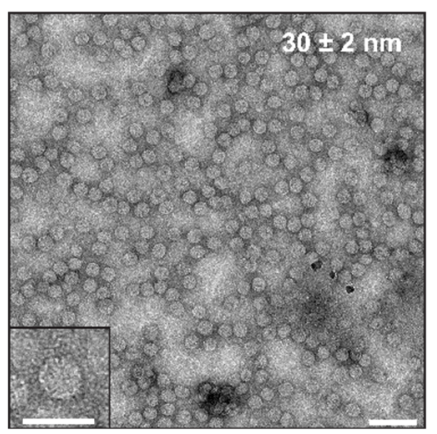

pH-induced $T=3$ capsids

Figure S6: Characterization of purified C59S VW1-VW8 ELP-CCMV: A. SDS-PAGE; B. LC-MS Q-TOF mass spectrum, Calculated MW 22411.5 $\mathrm{Da}$, Observed $22411 \mathrm{Da}$; C. Transmission electron microscopy of ELP-induced capsids ( $23 \pm 3 \mathrm{~nm} ; \mathrm{N}=50)$ and pH-induced capsids ( $30 \pm 2$ $\mathrm{nm} ; \mathrm{N}=50$ ), Scale bar $100 \mathrm{~nm}$, zoomed-scale bar $50 \mathrm{~nm}$.

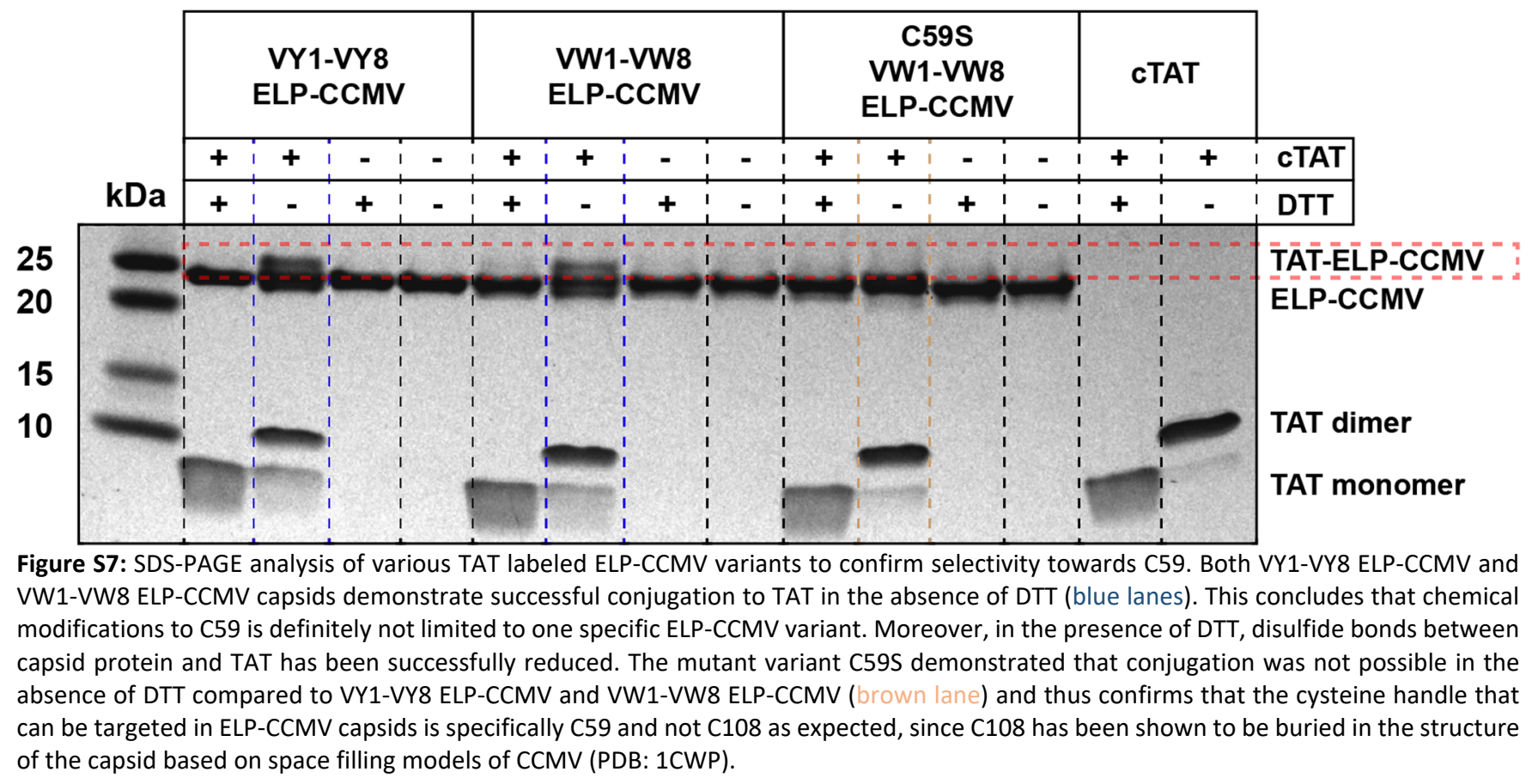


A.

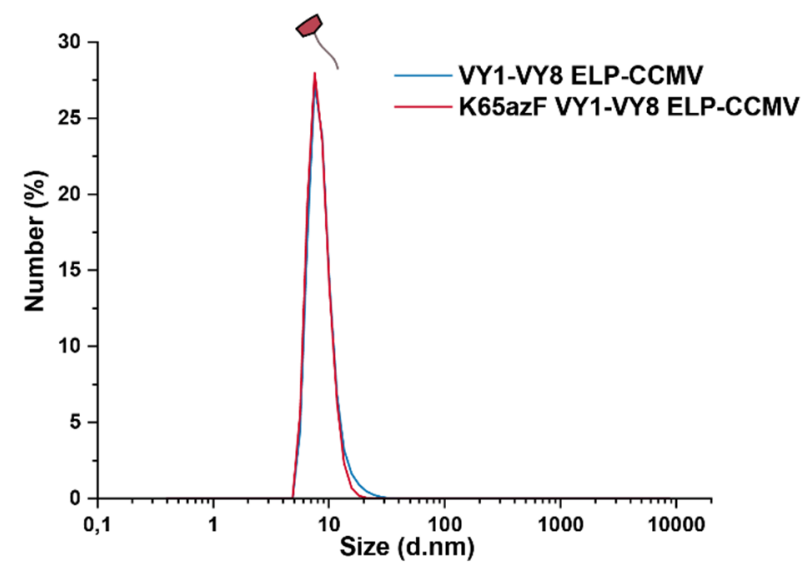

B.

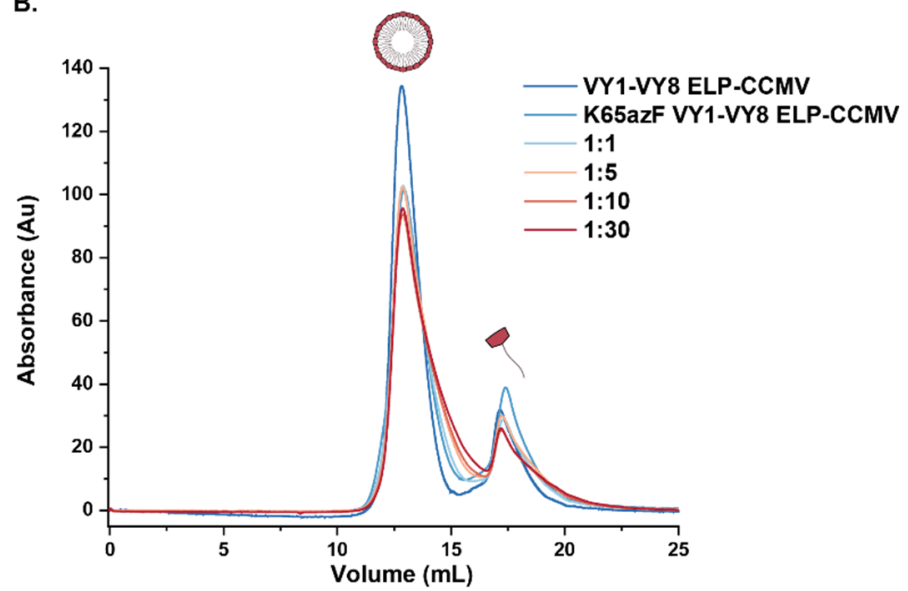

Figure S8 A) Dynamic light scattering of VY1-VY8 ELP-CCMV and K65azF VY1-VY8 ELP-CCMV dimers by dialyzing towards pH $7.5100 \mathrm{mM}$ $\mathrm{NaCl}$ Buffer prior to mixing in stated ratio's. B) Size exclusion chromatography results of VY1-VY8 ELP-CCMV, K65azF VY1-VY8 ELP-CCMV and the mixed ratios of K65azF VY1-VY8 ELP-CCMV: VY1-VY8 ELP-CCMV (ELP-induced VLPs, elution volume $13 \mathrm{~mL}$ ). Absorbance measured at $280 \mathrm{~nm}$.

A.

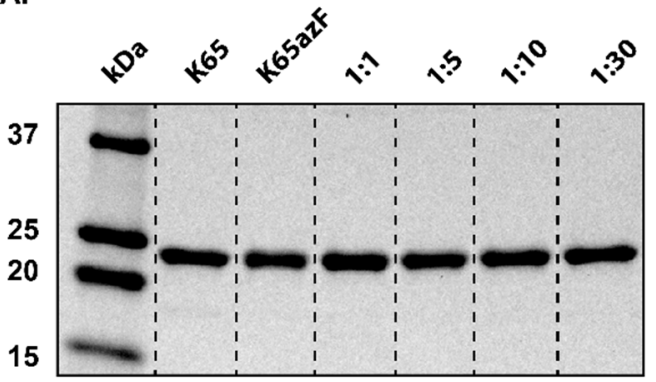

B.

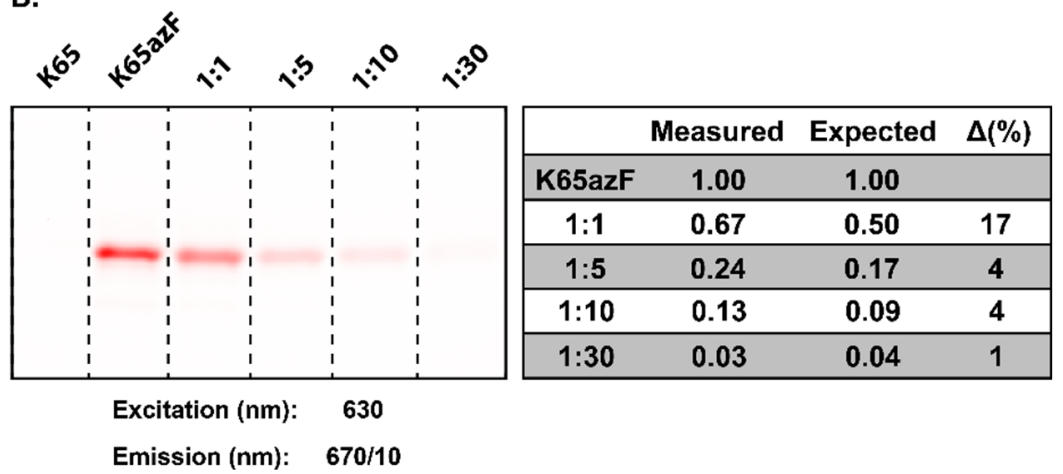

Figure S9: Cy5-labeled K65azF VY1-VY8 ELP-CCMV (via the azide handle) mixed with unlabeled VY1-VY8 ELP-CCMV capsid proteins in various ratios as indicated. A) Coomassie stained SDS-PAGE B) False color images obtained by illumination of Cy5 at $630 \mathrm{~nm}$ and emission through a 670/10 nm (Cy5) emission filter (Left); Quantification of the fluorescent signal normalized to the K65azF VY1-VY8 ELP-CCMV labeled capsids (Right). 


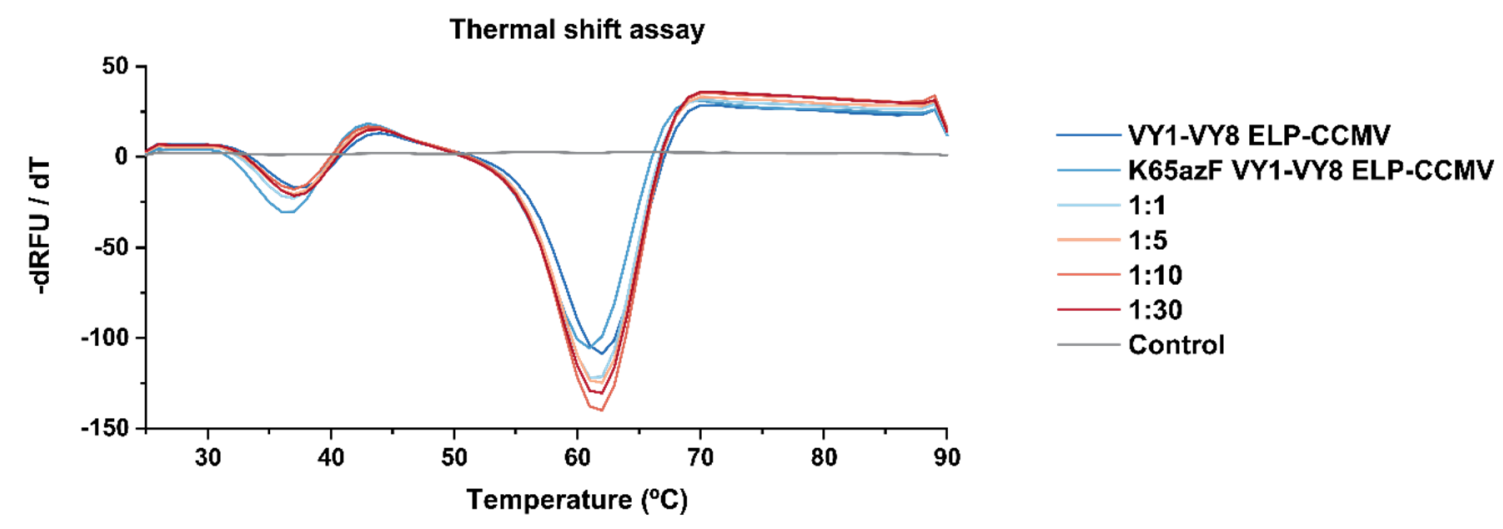

Figure S10: Thermal shift assay. First deviation of the SYPRO orange raw fluorescence signal. Capsids (5 $\mu \mathrm{M})$ of VY1-VY8 ELP-CCMV, K65azF VY1-VY8 ELP-CCMV and the mixed ratios of K65azF VY1-VY8 ELP-CCMV:VY1-VY8 ELP-CCMV demonstrate a similar stability (61-62 $\left.{ }^{\circ} \mathrm{C}\right)$ compared to VY1-VY8 ELP-CCMV $\left(62^{\circ} \mathrm{C}\right)$ in $\mathrm{pH} 7.5500 \mathrm{mM} \mathrm{NaCl}$ buffer. The melting temperature at approximately $37^{\circ} \mathrm{C}$ is most probably related to a small population of capsid proteins in solution.

A.

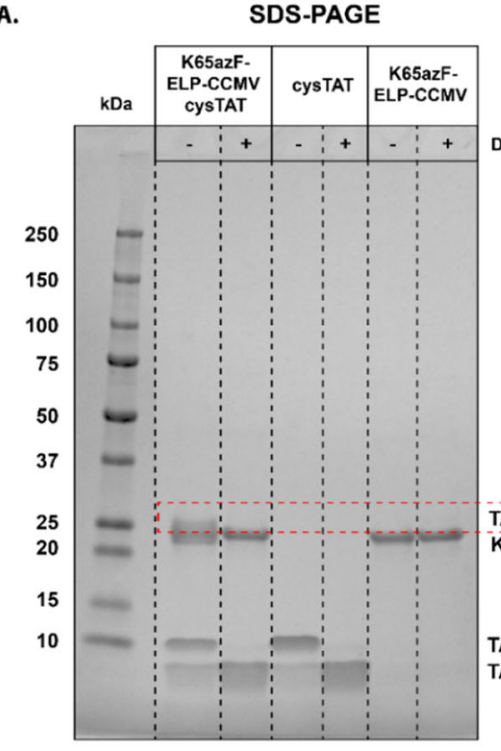

B.

LC-MS Q-TOF

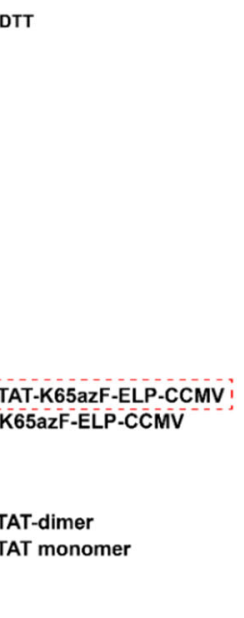

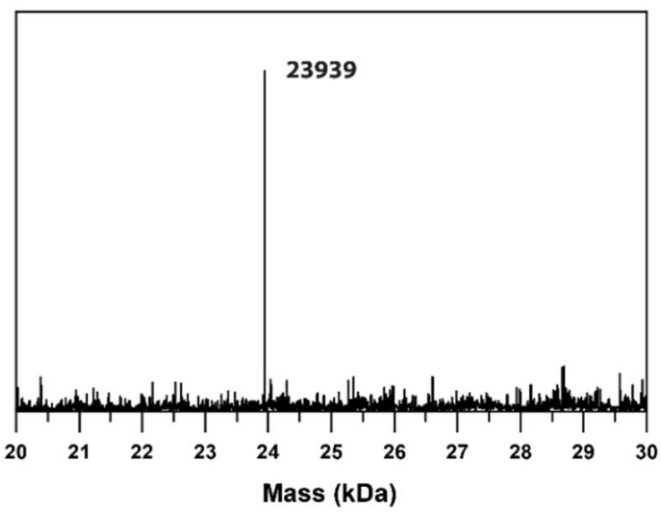

c.

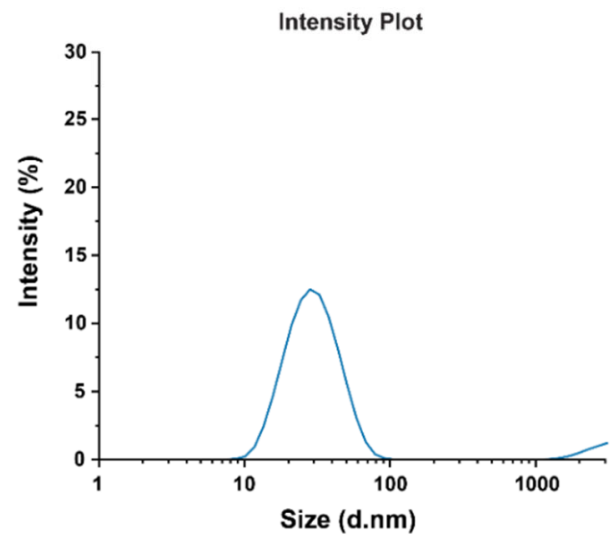

Dynamic Light Scattering

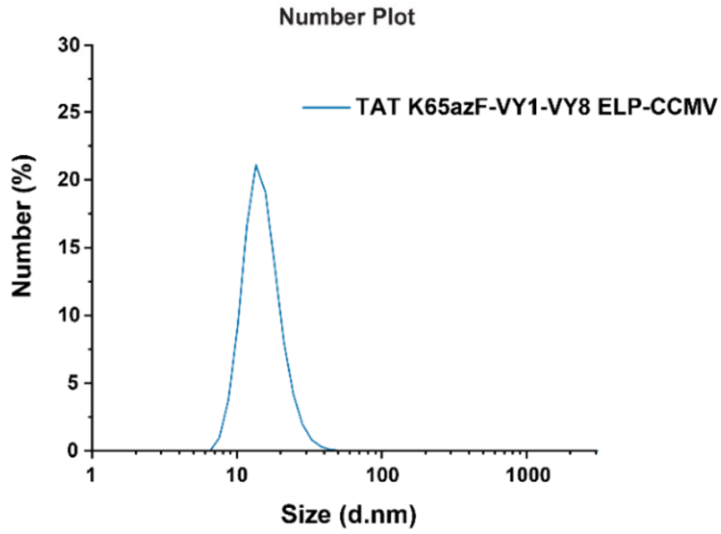

Figure S11: Characterization of TAT labeled K65azF-VY1-VY8 ELP-CCMV. A. SDS-PAGE analysis the labeling reaction using a protein (Coomassie) stained gel. SDS-PAGE analysis demonstrated successful conjugation of TAT to the capsid proteins with a yield of $45 \%$ ( 27 TAT peptides per $T=1$ capsid).B. LC-MS Q-TOF, mass spectrum of purified TAT labeled capsid proteins; Calculated MW 23939.4 Da, Observed 23939 Da. C. Dynamic Light Scattering, Intensity plot (Left), Number plot (Right) of TAT labeled K65azF-VY1-VY8 ELP-induced capsids in PBS containing $500 \mathrm{mM} \mathrm{NaCl}$. 


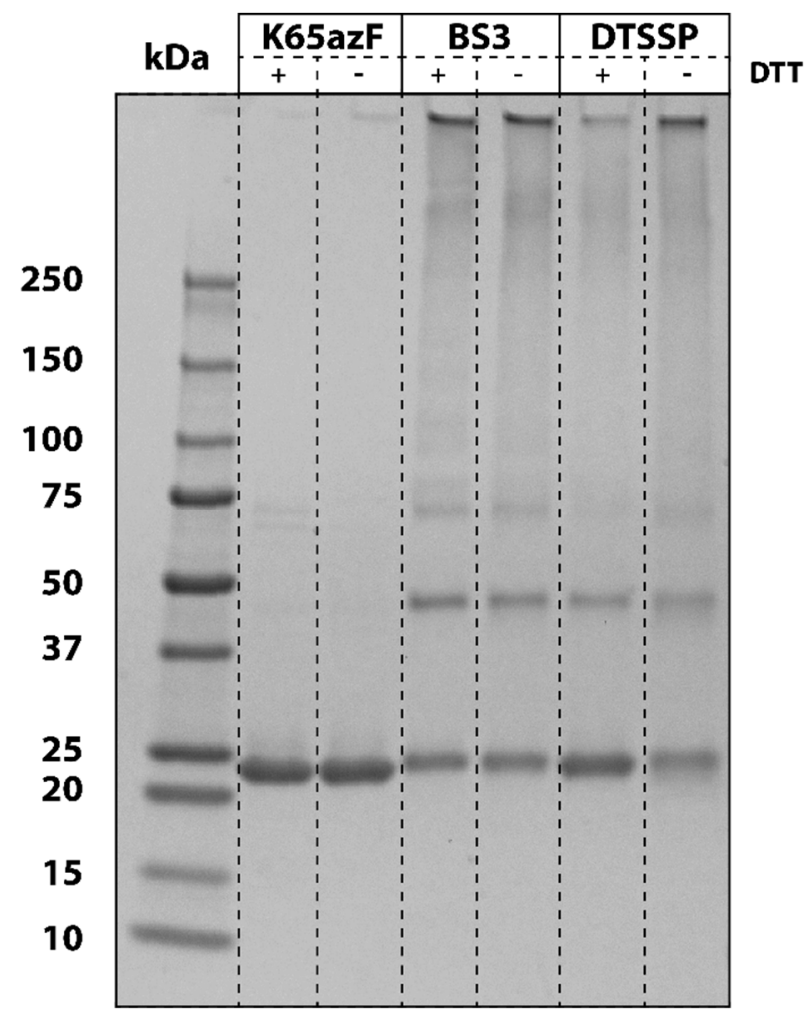

Figure S12: SDS-PAGE analysis of K65azF VY1-VY8 ELP-CCMV and stabilized K65azF ELP-CCMV by either using the BS3 or DTSSP crosslinker. Whereas the DTSSP crosslinker can be partly reduced in the presents of DTT, the BS3 linker cannot be broken down due to the lack of a disulfide bond. For both BS3 and DTSSP stabilized particles higher-ordered structures demonstrated that both homobifunctional crosslinkers stabilize the capsid in a similar matter.

A.

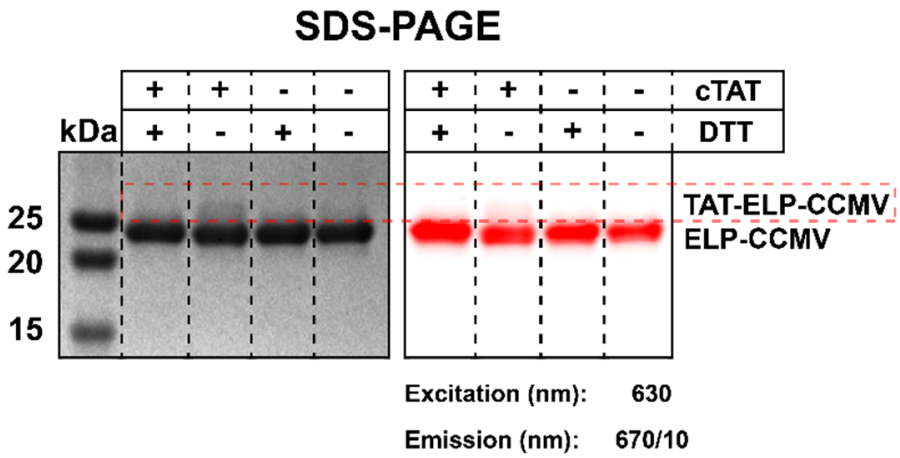

\section{B. Transmission Electron Microscopy}

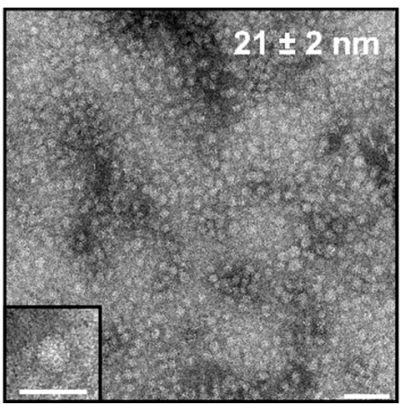

Figure S13: Characterization of dual-labeled K65azF VY1-VY8 ELP-CCMV capsids stabilized with BS3 and with i) TAT via disulfide bond formation, ii) Cyanine5 via a DBCO-azide reaction. A) SDS-PAGE analysis of dual-labeled capsids (sample 1 and 2) and Cyanine5 labeled K65azF ELP-CCMV capsids (sample 3 and 4). Due to the formation of capsid protein multimers (via capsid stabilization with BS3), the conjugation percentage could not be determined precisely. Nevertheless, labeling of TAT was confirmed, since the TAT \& Cyanine5 K65azF ELP-CCMV capsids under reducing conditions (sample 1) lack an additional band approximately $1.5 \mathrm{kDa}$ higher compared to the capsids in non-reducing conditions (sample 2). The degree of labeling was calculated for both dual labeled capsids and Cyanine5 labeled capsids. Both the dual labeled and Cyanine5 labeled capsids contain 8 dyes per capsid on average. B) Transmission electron microscopy images of dual-labeled capsids in PBS (21 $\pm 2 \mathrm{~nm} ; \mathrm{n}=50)$, Scale bar $100 \mathrm{~nm}$, zoomed-scale bar $50 \mathrm{~nm}$. 


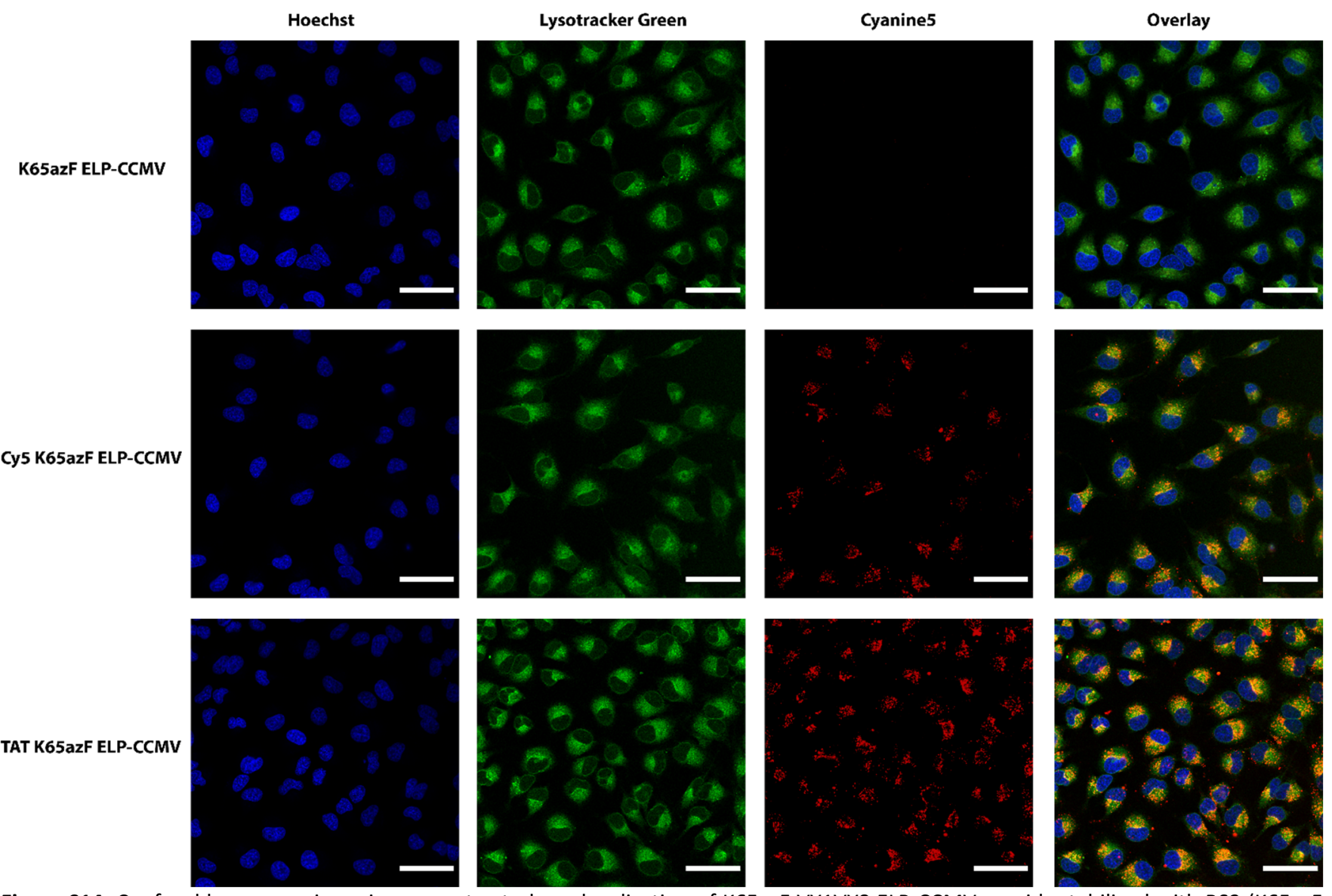

Figure S14: Confocal laser scanning microscopy to study co-localization of K65azF VY1VY8 ELP-CCMV capsids stabilized with BS3 (K65azF ELP-CCMV), and capsids additionally modified with Cyanine5 (Cy5 K65azF ELP-CCMV) and TAT (TAT K65azF ELP-CCMV). Color description; Blue $=$ Hoechst, Green $=$ Lysotracker Green, Red $=$ Cyanine5). Scale bar $50 \mu \mathrm{m}$.

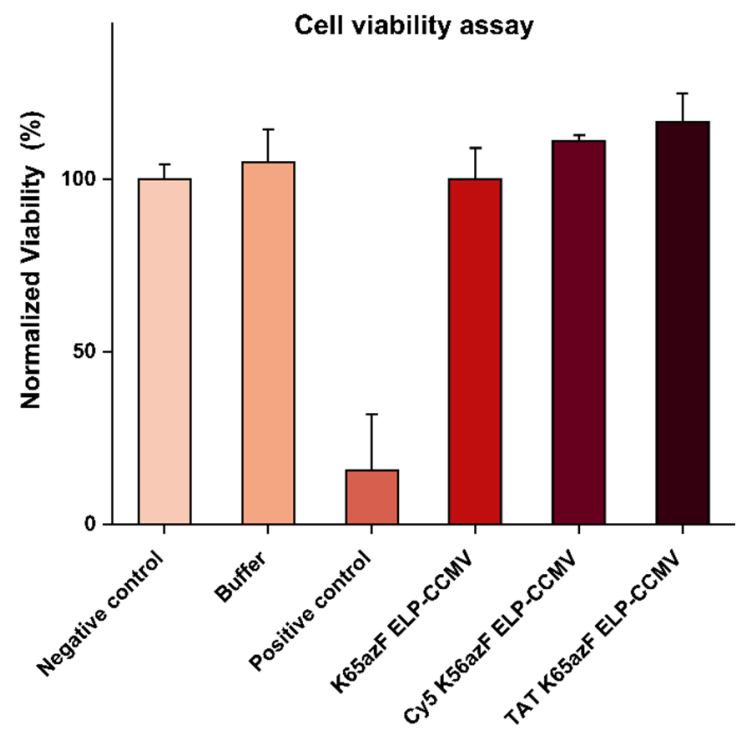

Figure S15: Alamar Blue cell viability assay. HeLa cells were incubated 24 hours with capsids at $37^{\circ} \mathrm{C}, 5 \% \mathrm{CO}_{2}$. Cells were then washed, and Alamar Blue reagent was diluted in Opti-MEM and added to the cells for 60 minutes. Fluorescence was measured with a microplate reader (excitation: $530 \mathrm{~nm}$; emission: $590 \mathrm{~nm}$ ). Mean values were normalized to untreated cells (negative control). PBS (Buffer) was added to cells to determine whether the buffer, used to dilute the particles, had an effect on the cell viability. The positive control was obtained with a cell lysis solution. 


\section{Uncropped SDS-PAGE gels}

\begin{tabular}{|c|c|c|c|c|c|c|c|c|}
\hline kDa & \multicolumn{2}{|c|}{ ELP } & \multicolumn{3}{|c|}{$\begin{array}{l}\text { Native } \\
\text { CCMV }\end{array}$} & \multicolumn{3}{|c|}{$\begin{array}{c}\text { Dye } \\
\text { control }\end{array}$} \\
\hline 250 & +1 & - & $1+$ & $1=$ & $\begin{array}{l}1 \\
1\end{array}$ & + & $\begin{array}{l}1 \\
1\end{array}$ & - \\
\hline 50 & I & & 1 & 1 & 1 & & 1 & \\
\hline- & I & & 1 & I & 1 & & 1 & \\
\hline$\longrightarrow$ & I & & 1 & I & 1 & & 1 & \\
\hline- & 1 & & 1 & 1 & 1 & & 1 & \\
\hline 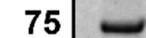 & 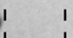 & & 1 & I & 1 & & 1 & \\
\hline & I & & 1 & I & 1 & & 1 & \\
\hline & 1 & & 1 & I & 1 & & 1 & \\
\hline 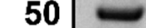 & 1 & & 1 & 1 & 1 & & 1 & \\
\hline & 1 & & 1 & I & 1 & & 1 & \\
\hline- & 1 & & 1 & 1 & 1 & & 1 & \\
\hline & 1 & & 1 & 1 & I & & I & \\
\hline 5 & 1 & & 1 & 1 & 1 & & 1 & \\
\hline & i & & $1=$ & $1=$ & & & I & \\
\hline & I & I & 1 & I & 1 & & 1 & \\
\hline 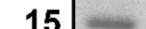 & 1 & & 1 & I & 1 & & 1 & \\
\hline & 1 & & 1 & 1 & 1 & & 1 & \\
\hline$=$ & 1 & I & 1 & 1 & I & & 1 & \\
\hline & 1 & 1 & 1 & 1 & I & & 1 & \\
\hline & 1 & 1 & 1 & 1 & I & & 1 & \\
\hline
\end{tabular}
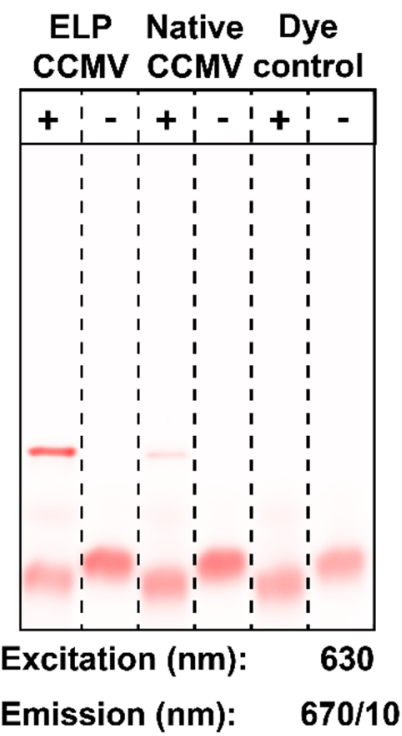

Figure S16: Uncropped SDS-PAGE analysis of Figure 2.

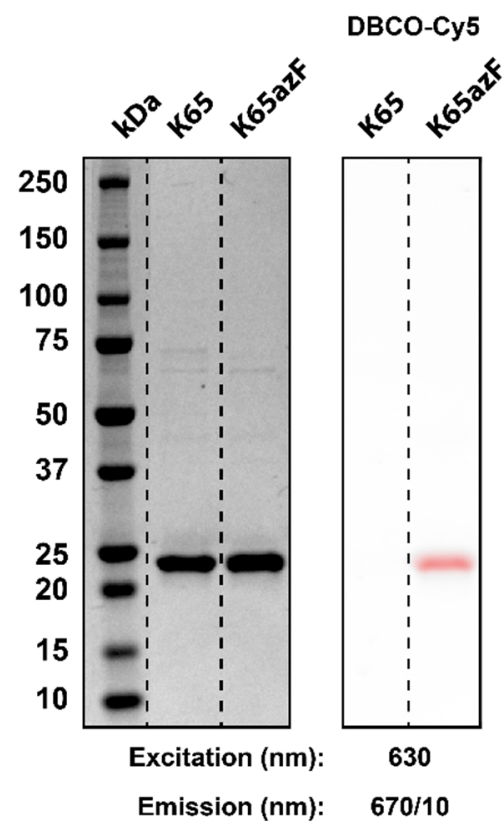

Figure S17: Uncropped SDS-PAGE analysis of Figure 5A. 


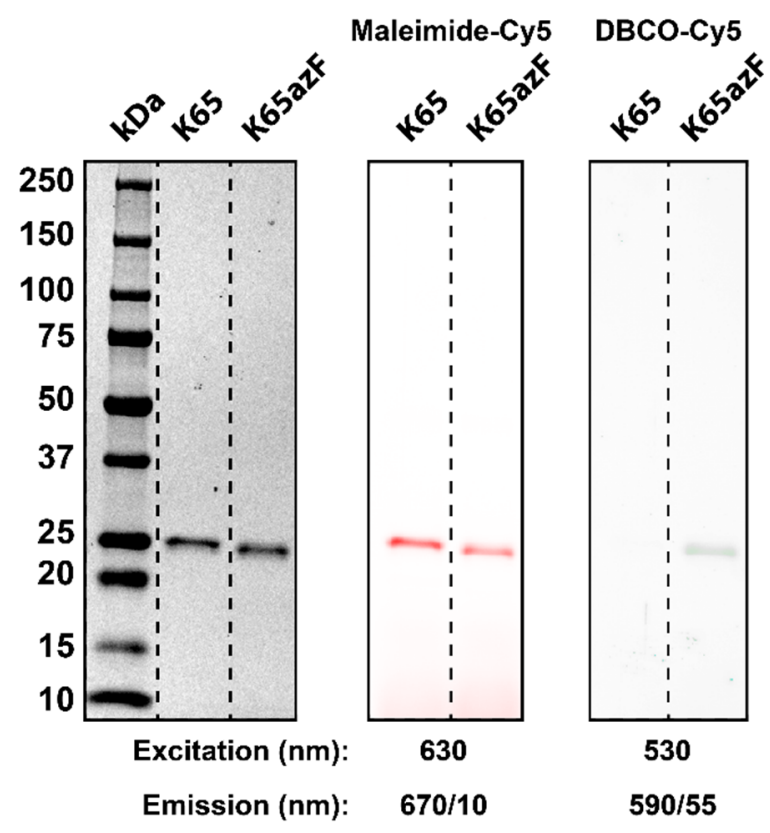

Figure S18: Uncropped SDS-PAGE analysis of Figure 5B.

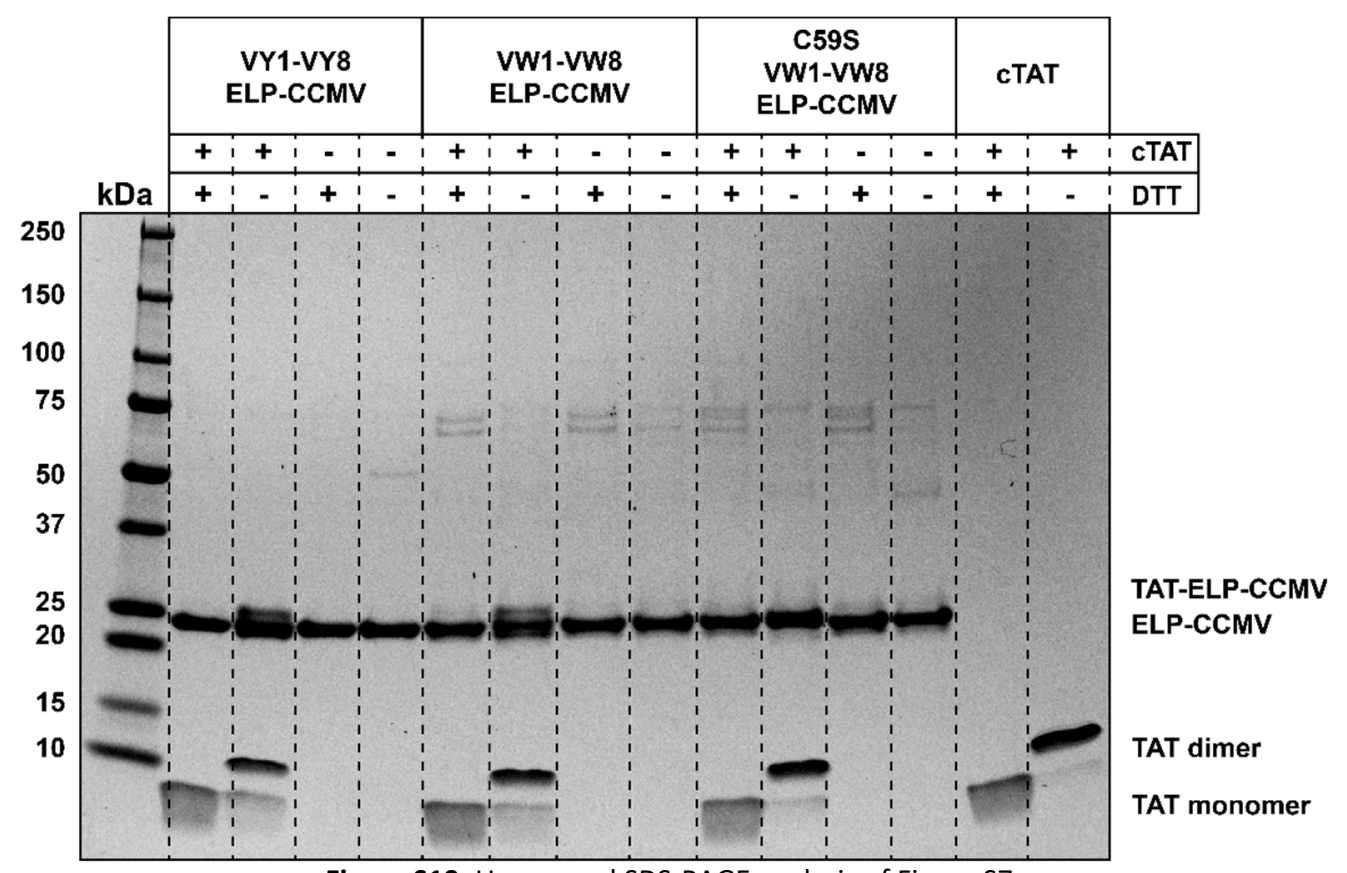

Figure S19: Uncropped SDS-PAGE analysis of Figure S7. 

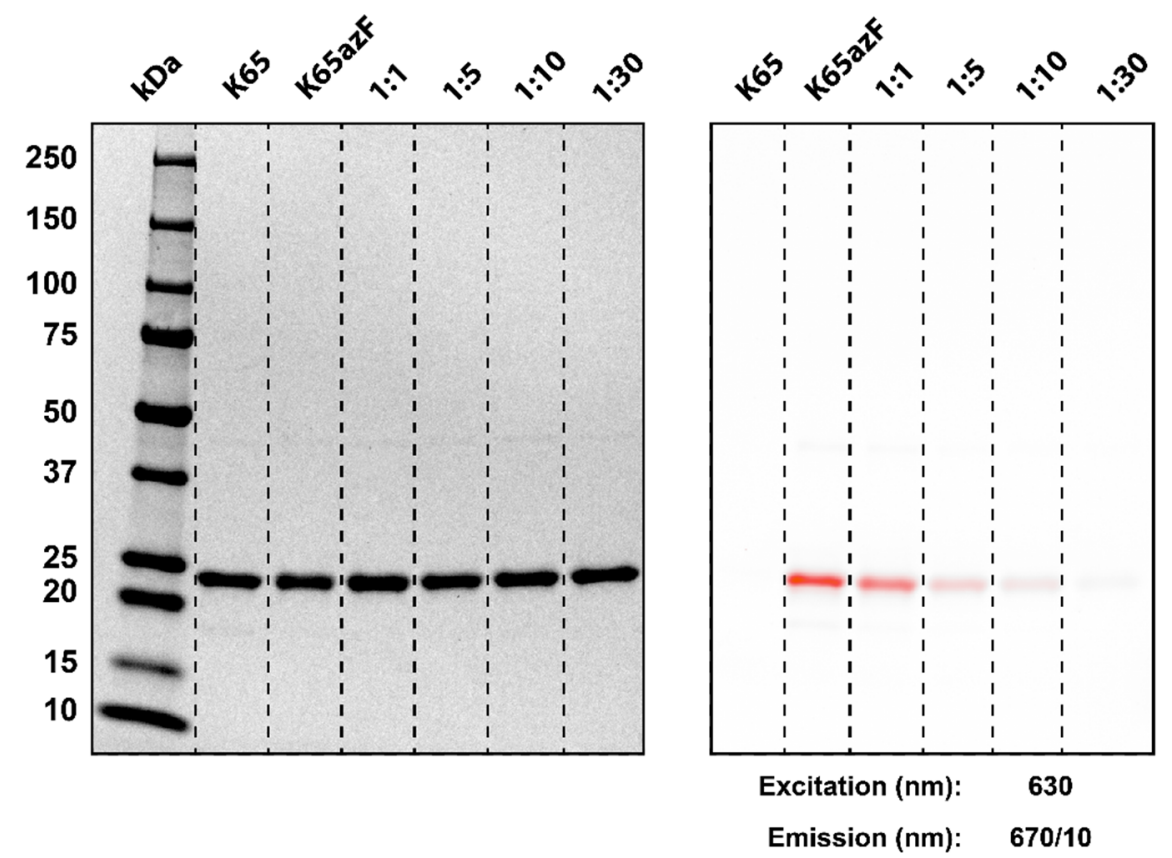

Figure S20: Uncropped SDS-PAGE analysis of Figure S9.

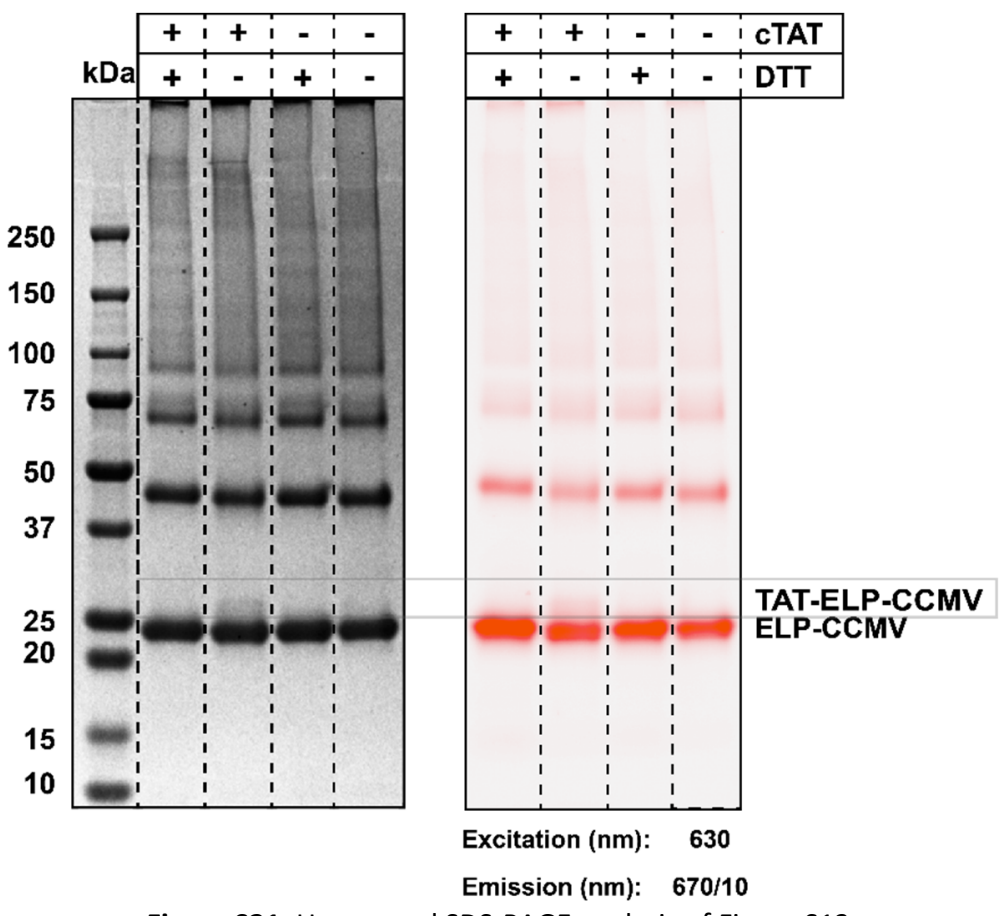

Figure S21: Uncropped SDS-PAGE analysis of Figure S13. 


\section{References}

1 van Eldijk, M. B.; Wang, J. C.-Y.; Minten, I. J.; Li, C.; Zlotnick, A.; Nolte, R. J. M.; Cornelissen, J. J. L. M.; van Hest, J. C. M. Designing Two Self-Assembly Mechanisms into One Viral Capsid Protein. J. Am. Chem. Soc. 2012, 134, 18506-18509.

2 Schoonen, L.; Maas, R. J. M.; Nolte, R. J. M.; van Hest, J. C. M. Expansion of the Assembly of Cowpea Chlorotic Mottle Virus towards Non-Native and Physiological Conditions. Tetrahedron 2017, 73 (33), 4968-4971.

3 Liu, H.; Naismith, J. H. An Efficient One-Step Site-Directed Deletion, Insertion, Single and Multiple-Site Plasmid Mutagenesis Protocol. BMC Biotechnol. 2008, 8, 91. 